\title{
Interaction of Egocentric and World-Centered Reference Frames in the Rat Posterior Parietal Cortex
}

\author{
Aaron A. Wilber, Benjamin J. Clark, Tyler C. Forster, Masami Tatsuno, and Bruce L. McNaughton \\ Canadian Centre for Behavioural Neuroscience, The University of Lethbridge, Lethbridge, Alberta, Canada T1K 3M4
}

\begin{abstract}
Navigation requires coordination of egocentric and allocentric spatial reference frames and may involve vectorial computations relative to landmarks. Creation of a representation of target heading relative to landmarks could be accomplished from neurons that encode the conjunction of egocentric landmark bearings with allocentric head direction. Landmark vector representations could then be created by combining these cells with distance encoding cells. Landmark vector cells have been identified in rodent hippocampus. Given remembered vectors at goal locations, it would be possible to use such cells to compute trajectories to hidden goals. To look for the first stage in this process, we assessed parietal cortical neural activity as a function of egocentric cue light location and allocentric head direction in rats running a random sequence to light locations around a circular platform. We identified cells that exhibit the predicted egocentric-byallocentric conjunctive characteristics and anticipate orienting toward the goal.
\end{abstract}

Key words: spatial orientation; landmark navigation; posterior parietal cortex; head direction; spatial navigation; allocentric

\section{Introduction}

Experimental and theoretical work suggests that animals might use vector-based computations to navigate to hidden goals (Collett et al., 1986; Cheng, 1988; Gallistel, 1990). Such computations require storage of vectors defining the direction and distance between a landmark and a current location, which may become a future goal. McNaughton et al. (1995) proposed that hippocampal neurons, which form an ensemble code for location (O'Keefe and Dostrovsky, 1971; Wilson and McNaughton, 1993), also encode the bearing and distance of environmental landmarks, an idea supported by the observations that "place" cells can be controlled by the location of visual cues (Gothard et al., 1996; Knierim, 2002; Knierim and Rao, 2003), and that other hippocampal neurons fire at a specific distance and direction relative to some objects ("landmark vector cells"; Deshmukh and Knierim, 2013 and see below).

McNaughton et al. (1995) suggested that hippocampal landmark vector cells may be generated via coordinate transformations involving cells that fire as a function of allocentric (world-centered) heading and cells that encode the landmark direction in egocentric coordinates (e.g., landmark is $90^{\circ}$ to

\footnotetext{
Received Jan. 25, 2014; revised March 3, 2014; accepted March 7, 2014.

Author contributions: A.A.W. and B.L.M. designed research; A.A.W. and T.C.F. performed research; A.A.W., B.J.C., T.C.F., M.T., and B.L.M. analyzed data; A.A.W., B.J.C., and B.L.M. wrote the paper.

This research was supported by the Alberta Innovates Health Solutions Polaris Award to B.L.M., MH46823-16 to B.L.M., and Alberta Innovates Health Solutions Fellowships to A.A.W. and B.J.C. We thank Dr. Valery Bouquet for technical assistance with the software for the apparatus; Jessica Vos and Karim Ali for technical assistance with data analysis; Valerie Lapointe for helpful comments on the figures; and Drs. Vincent Bonin, Bryan Kolb, Artur Luczak, Robert McDonald, Jake Ormond, Cara Wellman, and lan Whishaw for helpful comments on this manuscript. The data reported here are available upon request.

The authors declare no competing financial interests.

Correspondence should be addressed to Aaron Wilber, Canadian Centre for Behavioural Neuroscience, University of Lethbridge, 4401 University Drive West, Lethbridge, AB T1K 3M4. E-mail: aaron.wilber@uleth.ca.

DOI:10.1523/JNEUROSCI.0511-14.2014

Copyright $\odot 2014$ the authors $\quad 0270-6474 / 14 / 345431-16 \$ 15.00 / 0$
}

the right). Such cells could combine on common postsynaptic targets to produce "conjunctive" units that encode a specific combination of both reference frames and could be used to derive the allocentric direction of the landmark (i.e., the landmark bearing independent of head direction; Fig. 1A). This signal, in combination with information about distance to the landmark, could endow hippocampal neurons with landmark vector-firing characteristics.

Posterior parietal cortex (PPC), which is connected to the hippocampus via indirect entorhinal cortex projections (Vogt and Miller, 1983; Jones and Witter, 2007), is likely to be involved in the first steps of this coordinate transformation. Lesion studies indicate that the PPC is critical for spatial orientation in the rat (Kolb and Walkey, 1987; Kolb et al., 1994), and cells that fire as a function of an animal's head direction have been identified there (Chen et al., 1994a,b). Finally, studies in primates found that some PPC cells encode cue position in retina-centered coordinates and are modulated by passive body rotation (Snyder et al., 1998), suggesting that the PPC may integrate world-centered (allocentric) heading and egocentric information (retinotopic position of the cue); however, these studies were conducted under restraint, so it is unknown how such cells might respond during free movement in space, particularly given that the sharp tuning of hippocampal place cells and head direction cells can be dramatically degraded by restraint (Foster et al., 1989; Taube, 1995; Knierim et al., 1998).

We assessed the hypothesis that PPC neurons encode spatial heading as a function of egocentric and allocentric coordinates in rats performing a random spatial sequence task involving navigation to 32 rewarded locations around the perimeter of a platform (Fig. 1B). Each location was marked by a blinking light, which acted as a landmark for navigation to the correct reward site (Fig. 2). By using cue lights as "landmarks," rats were required to cover the full range of headings and cue directions at several spatial locations. 
A

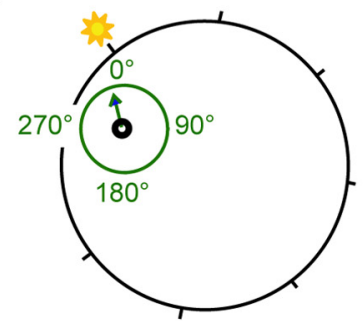

Landmark Bearing

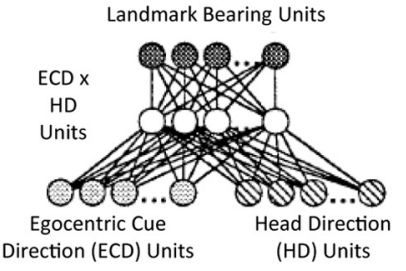

B

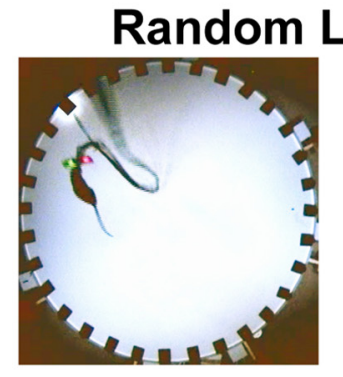

C Head Direction

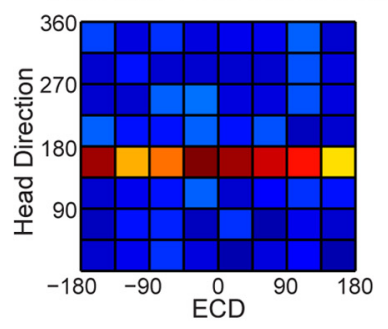

Direction (ECD) Units

\section{ghts Task}
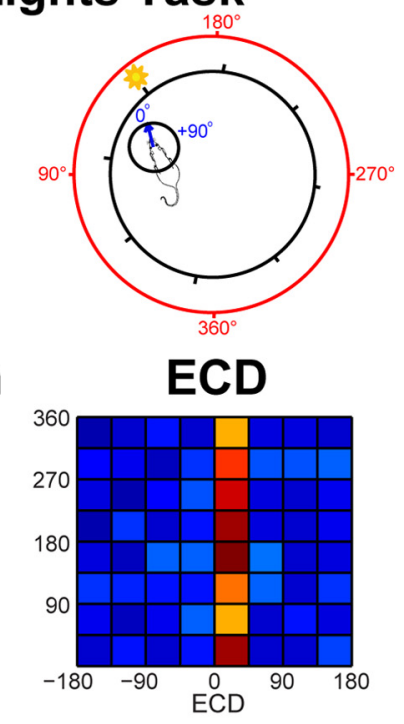

D
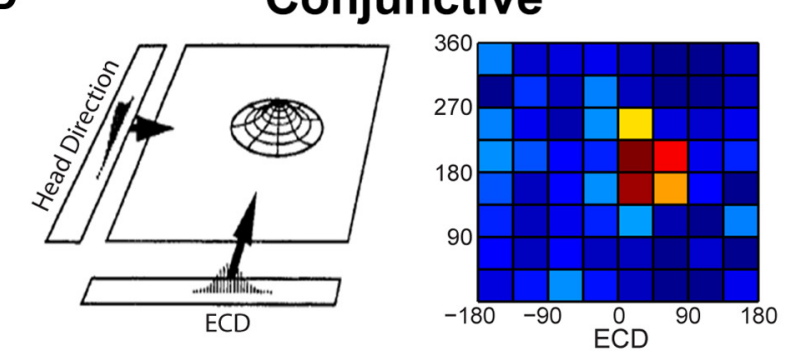

Figure 1. Apparatus, reference frames, and hypothetical response profile for the ECD (egocentric cue direction), head direction, and conjunctive functional cell types. $A$, Left, Schematic of landmark bearing. Landmark bearing is derived from the position of the cue light with respect to a point in the center of the rat's head. In the video frame shown in $\boldsymbol{B}$, the landmark bearing is $\sim 330^{\circ}$. Right, Wiring diagram illustrating hypothetical cell types that could produce landmark bearing units. The population of ECD $\times$ head direction cells would provide information about the current landmark ECD and head direction. A specific combination of ECD and head direction corresponds to a single landmark bearing. Thus, landmark bearing cells could "read out" the landmark bearing from the population of ECD $\times$ head direction cells. $\boldsymbol{B}$, Left, Apparatus. Rats are trained to run a random spatial sequence to 32 light locations. This task requires the rat to cover the full range of headings and ECDs at a wide range of spatial locations. Right, Schematic of ECD and head direction for the same video frame. Head direction is derived from the position of the two colored domes, which are fixed with respect to the head. In this video frame, the ECD is approximately $+10^{\circ}$ and the head direction is $\sim 160^{\circ}$. C, Hypothetical conjunctive plots (firing rate per $45^{\circ}$ of ECD and head direction) for an ideal head direction-only cell (left; horizontal band of high activity spans range of ECDs) and for an ideal ECD-only cell (right; band of high activity spanning range of head directions). $\boldsymbol{D}$, Left, Head direction and ECD units could combine to produce units which, if thresholded appropriately, would encode a specific combination of both reference frames (adapted from McNaughton et al., 1995). Right, Hypothetical conjunctive plot. Conjunctive cells encode neither head direction nor ECD but a specific combination of these two reference frames.

\section{Materials and Methods}

Male Fisher-Brown Norway hybrid rats $(n=8), 5-10$ months of age, underwent surgery for implantation of bilateral stimulating electrodes aimed at the medial forebrain bundle (MFB; $2.8 \mathrm{~mm}$ posterior from bregma, $1.7 \mathrm{~mm}$ from midline, $7.8 \mathrm{~mm}$ ventral from dura). Before surgery rats were housed $2-3$ per cage. After recovery from surgery, rats were trained to nose poke for MFB stimulation. Then brain stimulation parameters $(200 \mu$ s half cycle, $150 \mathrm{~Hz}$ biphasic $70-110 \mu \mathrm{A}$ current applied for $300-450 \mathrm{~ms}$ ) were adjusted to find the minimal intensity and duration for maximal responding. Next, rats with optimal MFB stimulation ( $N=4$ of the 8 with stimulating electrodes) underwent surgery to implant a custom 18-tetrode bilateral "hyperdrive" $(n=3$; similar to Kloosterman et al., 2009; Nguyen et al., 2009) or 18-tetrode unilateral hyperdrive aimed at the left PPC ( $n=1$; identical to Kloosterman et al., 2009; Nguyen et al., 2009).

\section{Controls for MFB stimulation effects}

MFB stimulation was necessary to obtain sufficient trials for some analyses. For example, complete coverage (i.e., samples for all bins) for the conjunctive plots of head direction for each egocentric cue direction (ECD; Fig. 3) require $\sim 300$ trials. To ameliorate concerns about MFB effects on PPC neural activity, data were removed for the brain stimulation duration plus an additional poststimulation $50 \mathrm{~ms}$ blackout period (Bower et al., 2005; Euston and McNaughton, 2006; Euston et al., 2007; Johnson et al., 2010). In addition, MFB stimulation was delivered in one hemisphere and recordings were obtained from both hemispheres from most rats ( $n=3$ of 4$)$. For these rats we compared the proportion of cells that fell into each of our main cell-type categories (head direction-only, ECD-only, conjunctive, and self-motion-only) in the same versus opposite hemisphere to brain stimulation. There were no differences in proportion of cells between hemispheres for any of the cell types $\left(\chi_{s(1)}^{2}<\right.$ 2.16 , ps $>0.14)$. Further, in previous experiments where it was possible to obtain sufficient coverage for analyses using food reward, identical results were obtained using MFB stimulation and food reward, suggesting that the results obtained from MFB experiments are generalizable (Euston and McNaughton, 2006). This suggests MFB stimulation did not directly influence the activity patterns we observed.

\section{Surgical procedure}

Hyperdrives consisted of 18 tetrodes and 3-4 reference electrodes. Each tetrode consisted of four polyimide-coated, nichrome wires (14 $\mu \mathrm{m} \mathrm{di-}$ ameter) twisted together. The hyperdrives were positioned over the PPC (centered $4.5 \mathrm{~mm}$ posterior from bregma and $\pm 2.95 \mathrm{~mm}$ from midline) to target the average PPC region based on connectivity (Kolb and Walkey, 1987; Reep et al., 1994; Torrealba and Valdes, 2008; Calton and Taube, 2009) and studies designed to characterize PPC contributions to navigation (Kolb and Walkey, 1987; Chen et al., 1994a; Rogers and Kesner, 2006; Calton and Taube, 2009); though slightly more posterior regions are included compared with the most recent recording studies (Nitz, 2006, 2012; Whitlock et al., 2008, 2012) due to an emphasis on the PPC region shown to encode allocentric (world centered) auditory cue position (Nakamura, 1999). Our recording coordinates are likely to correspond to the intersection of the mouse anteromedial, posteromedial, and mediomedial areas (Wang and Burkhalter, 2007; Wang et al., 2012).

\section{Behavior}

Training and testing took place on a large (1.5 m diameter) circular platform with 32 light cues evenly distributed around the perimeter (Fig. $1 B$; similar to 8-station apparatus; Bower et al., 2005). A custom computer program (interfaced with the maze via an FPGA card; National Instruments) controlled maze events, delivered MFB stimulation rewards via a Stimulus Isolator (World Precision Instruments) when the rat entered a $10 \mathrm{~cm}$ diameter zone in front of the active cue light, and generated a coded time stamp in the Neuralynx system for each maze event (e.g., light onset for a particular zone). First, alternation training was achieved using barriers to restrict the movement of the rat to alternating between a pair of cue lights on opposite sides of the maze. To ensure cues were visually salient, lights were flashed at $\sim 3 \mathrm{~Hz}$ (with equal on/off time) when activated. The first light was activated until the rat 


\section{Hippocampal Bearing By Distance Cells}

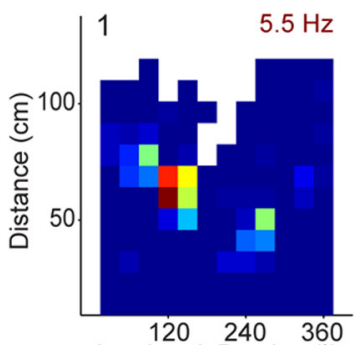

Landmark Bearing $\left(^{\circ}\right)$

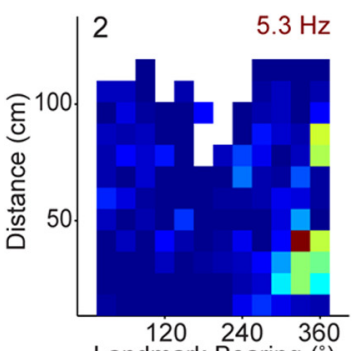

Landmark Bearing $\left({ }^{\circ}\right)$
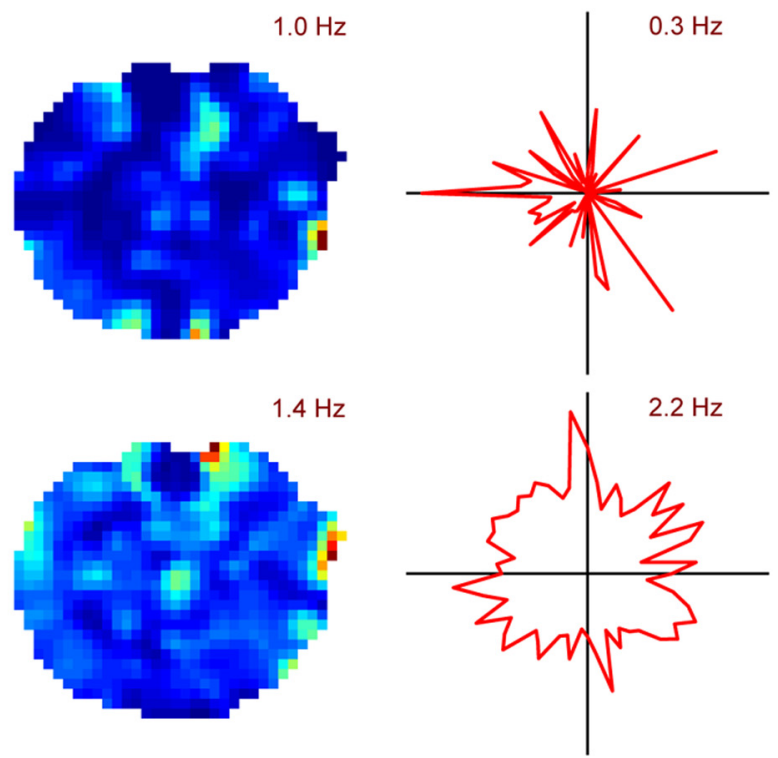

Figure 2. Landmark bearing by distance conjunctive cells may originate from egocentric and head direction units in the PPC. Two examples of hippocampal landmark bearing by distance cells. The hippocampal (CA1) data shown here were collected while rats ran a random spatial sequence to 32 light locations (Fig. $1 B$ ). The task required the rat to cover a wide range of cue light bearings (i.e., direction of the cue light independent of head direction) and distances at a wide range of spatial locations. Hippocampal bearing by distance cells have been reported previously (Deshmukh and Knierim, 2013) and were recorded here in the CA1 field of the hippocampus of each of two rats. Hippocampal data were recorded simultaneously with the PPC data reported here. Left, Conjunctive plot (firing rate per $30^{\circ}$ of cue light bearing and distance). Firing rate for cue light bearing and distance from the cue light (calculated in pixels and shown as centimeters for graphical purposes) suggests that these cells encode a specific combination of cue light distance and bearing. Middle, Place fields could confound a bearing by distance analysis (e.g., place field in the center of the maze); however, none of the landmark bearings by distance cells in our dataset had place fields. All colormaps range from 0 (dark blue) to the peak value indicated in maroon. Right, Head direction properties could be a confound for landmark bearing properties; however, none of the conjunctive bearings by distance cells in our dataset had head direction response properties. Smoothed spatial firing rate maps for the same cells. Firing rate per $6^{\circ}$ of head direction (red polar plot). Peak firing rate is indicated in maroon.

Table 1. Training and testing conditions

\begin{tabular}{llll}
\hline $\begin{array}{l}\text { Rat } \\
\text { number }\end{array}$ & $\begin{array}{l}\text { Random sequence } \\
\text { type }\end{array}$ & $\begin{array}{l}\text { Light/dark cycle } \\
\text { phase during } \\
\text { testing }\end{array}$ & $\begin{array}{l}\text { Number of } \\
\text { recording sessions }\end{array}$ \\
\hline 1 & 32-item random with repeats (up to $5 \times$ ) & Dark & 4 \\
2 & 32-item equal heading representation & Light & 4 \\
3 & Up to 900-item fully random & Light & 25 \\
4 & Up to 900-item fully random & Light & 23 \\
\hline
\end{tabular}

The same activity patterns were observed across four rats suggesting that neither learning, unequal representation of heading, nor light cycle phase contributed to the results. Recording sessions refers to daily sessions, which were typically split into two 50 min behavioral sessions separated by a 50 min rest session.

reached that reward zone and received MFB stimulation, and then the cue light in the opposite reward zone was activated. Alternation training continued until rats reached asymptote performance (rat $1=20 \mathrm{~d}$; rat $2=33 \mathrm{~d}$, rat $3=27 \mathrm{~d}$, and rat $4=9 \mathrm{~d}$ ). All of the data reported here comes from the next, random lights, task. In the random lights task, up to 900 light/reward zones were illuminated in a single session one at a time in a random order, with each light remaining active until the rat reached it. Data from four recording sessions (i.e., day sessions) for rat 1 were obtained with a 32 -item random sequence that repeated up to five times within a single behavioral session (i.e., individual $50 \mathrm{~min}$ sessions). A new random 32-item sequence was generated for each behavioral session (Table 1). Data from the rat 2 included a 32 -item pseudorandom sequence that was modified from a random sequence so that all headings in the room were equally represented. The same sequence was used for each of four recording sessions. Finally, for rats 3 and 4, 25 recording sessions and 23 recording sessions were obtained, respectively. For both rats 3 and
4 a random light sequence unique for each behavioral session (up to 900 items) was used to ensure that learning effects were not contributing to the activity patterns we observed. For rats 1 and 2 and half of the sessions for rat 3 , prominent distal cues were arranged around the perimeter of a large room $(\sim 4.5 \times 6 \mathrm{~m})$. For the remaining rats and sessions prominent cues (strips of white curtain) were displayed on one to two walls of a square curtain that hung $\sim 1 \mathrm{~m}$ beyond the edge of the apparatus. For all rats and sessions, dim ambient light illuminated the maze from above. Rat 1 was housed in a reverse light/dark cycle vivarium and tested during the dark cycle. Rats 2-4 were housed in a vivarium and were tested during the light cycle. The same activity patterns were observed across all four rats, suggesting that neither learning effects, unequal representation of heading directions, light cycle phase, nor distal cue configuration contributed to the activity patterns we observed. All experiments were performed in accordance with protocols approved by the University of Lethbridge Animal Welfare Committee and conformed to $\mathrm{Na}$ tional Institutes of Health Guidelines on the Care and Use of Laboratory Animals.

\section{Recording procedures}

A custom electrode interface board attached to the hyperdrive connected three unity-gain headstages (HS-27; Neuralynx) to the recording system (Neuralynx). Tetrodes were turned at the end of each day as needed, up to 60 $\mu \mathrm{m} / \mathrm{d}$, while monitoring the audio and visual signal of the unit activity. Once a large number of well isolated units in the PPC were obtained, alternation training commenced. Thresholded (adjusted before each session) spike waveforms (filtered $0.6-6 \mathrm{kHz}$, digitized at $32 \mathrm{kHz}$ and referenced to an electrode in corpus callosum) and time stamps were collected for up to 18 tetrodes and processed to remove data within the stimulation duration plus $50 \mathrm{~ms}$ (Bower et al., 2005; Euston and McNaughton, 2006; Euston et al., 2007; Johnson et al., 2010). Rat position and head direction were tracked using colored domes of reflective tape, which were created by covering $1 / 2$ styrofoam balls in reflective tape (Fig. $1 B$ ) and on-line position information was used to trigger MFB stimulation rewards. Position and head direction data were collected at $60 \mathrm{~Hz}$ as interleaved video (rats 1-3) or $30 \mathrm{~Hz}$ (rat 4) and coregistered with spikes and stimuli. Spike data were automatically overclustered using KlustaKwik (http://klustakwik.sourceforge.net; Harris et al., 2000) then manually adjusted using a modified version of MClust (A.D. Redish, University of Minnesota). Only spike clusters with $<0.4 \%$ of the spikes in the first $2 \mathrm{~ms}$ on the autocorrelation, $<15 \%$ cut (by the threshold) on plots of peak spike amplitude on one tetrode wire versus another and with well defined cluster boundaries, were included for analyses. Isolated units were not treated as unique unless (1) the tetrode was moved $>60 \mu \mathrm{m}$ from the previous session or (2) the tetrode was not moved between sessions but the distributions of spike clusters were clearly unrelated between the two sessions (similar to Wills et al., 2010). Cortical neurons can be classified into fastspiking (approximately $>10$ spikes/s, narrow afterhypolarizations, and waveform symmetry) and regular-spiking units ( $<10$ spikes/s and wide afterhypolarizations), which are thought to correspond to interneurons and pyramidal cells, respectively (McCormick et al., 1985; Connors and Gutnick, 1990; Jung et al., 1998; Homayoun and Moghaddam, 2007; Woloszyn and Sheinberg, 2012). While classifying cells into putative categories in this way does not definitively separate pyramidal cells and interneurons, attempting to classify cells 
A
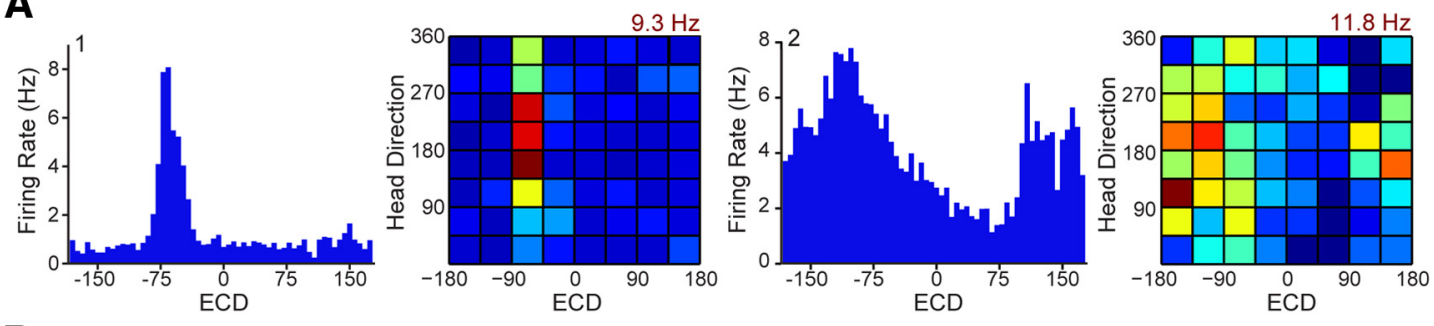

\section{B}
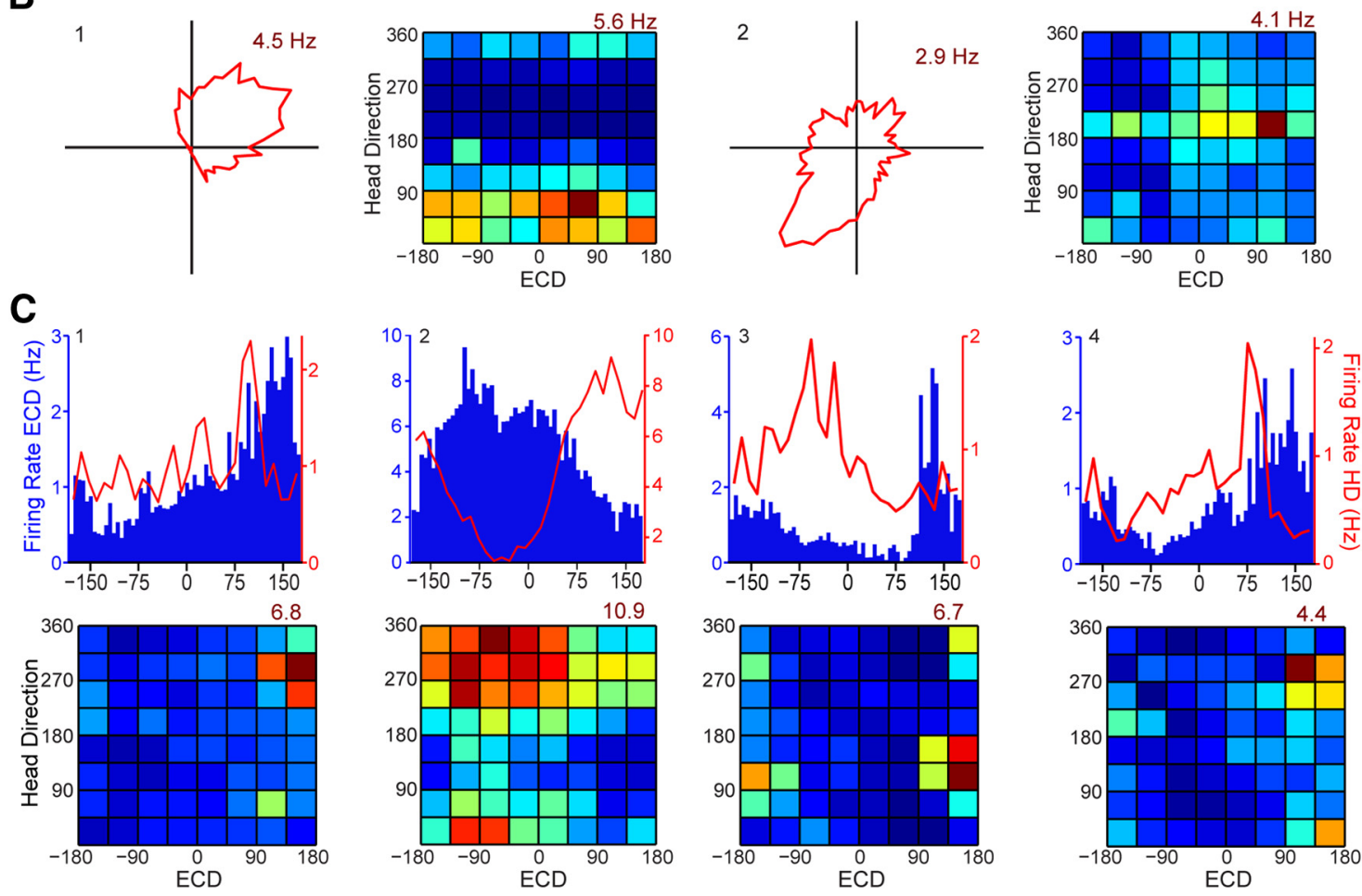

Figure 3. ECD cells, head direction cells, and conjunctive cells in the rat PPC. $A$, Two ECD cells chosen to illustrate the breadth of tuning. Firing rate per $6^{\circ}$ of ECD (blue bars) and corresponding conjunctive plots (colormaps). $\boldsymbol{B}$, Two head direction cells chosen to illustrate the breadth of tuning that is observed across head direction cells. Firing rate per $6^{\circ}$ of head direction (red polar plot) and corresponding conjunctive plots (colormaps). $A, B$, Conjunctive plots with vertical (ECD) and horizontal (head direction) bars of elevated activity confirm "only" classifications (based on our two-part Rayleigh and stability criteria). C, Four examples of conjunctive cells chosen to illustrate that there are both broadly and narrowly tuned conjunctive cells. Firing rate for $E C D$ (blue bars; $6^{\circ}$ bins) and head direction (HD; red line; $12^{\circ}$ bins; top row). To be categorized as a conjunctive cell, the Rayleigh had to be significant for head direction, the Rayleigh had to be significant for ECD, the head direction had to be stable across behavioral sessions, and the ECD had to be stable across behavioral sessions. Corresponding conjunctive plots (bottom row) confirm these cells actually encode a specific combination of the two reference frames. All colormaps have an evenly spaced color range from 0 (dark blue) to peak indicated in maroon.

in this manner is important. For example, longstanding disagreement about the role of primate inferotemporal cortex in visual object recognition was recently resolved by characterizing cells in this manner (Woloszyn and Sheinberg, 2012).

PPC data. Data recorded from a subset of the sessions (34 sessions) included cells that met the uniqueness criteria (above). Data from these 34 sessions were spike sorted and analyzed (rat $1=4$ sessions, rat $2=3$ sessions, rat $3=20$ sessions, and rat $4=7$ sessions). These data include 461 PPC cells (378 putative unique pyramidal cells and 83 putative unique interneurons) from four rats (number of putative unique PPC pyramidal cells/rat for rat $1=80$, rat $2=31$, rat $3=147$, and rat $4=$ 120). Each recording session (except for 5 of the 34 total sessions presented here) consisted of three rest sessions (data not shown) intermixed with two behavioral sessions on the apparatus to assess stability across behavioral sessions. For the five recording sessions where a single behavioral session was available, split $1 / 2$ measures of stability were used instead of assessing stability across two separate behavioral sessions.

Putative interneurons. The response properties of the putative interneurons in our sample were less specific. Consistent with previous reports (Hofer et al., 2011), there were no reliable examples of interneurons that fell into any of the cell types described here except the self- motion- "only" cell type. Further, interneurons that fell into this category were nonspecifically modulated by any motion state and not modulated by a single specific motion state (e.g., right turn), as was observed in putative pyramidal cells. Therefore, even though interneurons are likely to play a critical role in PPC function, the focus of the present paper is on putative pyramidal cells.

Hippocampal data. In addition, to confirm that our task engages the hippocampal landmark bearing cells described previously (Deshmukh and Knierim, 2013), we analyzed data recorded in dorsal CA1 field of the hippocampus simultaneously with the PPC data reported here (120 putative pyramidal cells recorded from three sessions for the first two rats). Thus, in total data from 581 putatively unique cells recorded in the hippocampus and PPC are described here.

\section{Head direction and ECD firing rate maps}

For the PPC data, cells not sufficiently active during maze sessions $(<250$ spikes/session; session $=\sim 50 \mathrm{~min}$ ) were excluded from all analyses (39 cells excluded so 339 putative pyramidal cells remained). Position and head direction data were used to calculate the angle of the cue light versus the rat head orientation for each video frame (i.e., egocentric cue position; Fig. $1 B$ ). Data from video frames in which head direction tracking 
was lost or segments in which the rat was still for long (60 s) relatively still periods (calculated from smoothed positioning data) were excluded. Then, ECD occupancy data were binned per $6^{\circ}$ of egocentric cue angle and converted to firing rate (spikes/s). Next, the same binning and firing rate conversion was applied to head direction data. Peak firing rate direction, mean vector magnitude, mean vector direction, change in mean/ peak vector direction, and Rayleigh statistics were calculated using a combination of custom MATLAB scripts and the circular statistics toolbox (Berens, 2009). Cells were classified as having ECD properties if they met our stringent two-part criteria. (1) They had a significant Rayleigh test for unimodal deviation from a uniform distribution for ECD firing rate corrected for binned data (Zar, 1999) and calculated by collapsing across the behavioral data for a single day's recording session $(p \leq 0.05)$. (2) They were stable (change in mean vector direction of $\leq 40^{\circ}$, which corresponds to $<7$ bins) across behavioral sessions (or split $1 / 2$ sessions). Cells were classified as having head direction properties if they met the same two-part criteria for the head direction firing rate vector: (1) Rayleigh test on the collapsed-across-behavioral-sessions firing rate data ( $p \leq 0.05$ ) and (2) were stable (change in peak vector direction of $<7$ bins, i.e., equivalent to the $\leq 40^{\circ}$ criteria for ECD cells) across behavioral sessions (or split $1 / 2$ sessions when data were not available for two consecutively recorded sessions). Previous studies have suggested that some cells in PPC, which appear to be head direction cells, are unstable (Chen et al., 1994a,b; Whitlock et al., 2012). Therefore, despite the risk of underestimating the percentage of cells in some of our functional cell-type categories, a measure of stability was necessary to ensure only stable cells were included for analyses. Head direction data were binned by $6^{\circ}$ for all statistical comparisons, stability testing, and head direction-only cell illustrations; however, for illustrative purposes only, data were binned by $12^{\circ}$ for head direction plots for conjunctive cells, as these cells tended to have more broad head direction tuning (e.g., Fig. $3 C$ ). Cells were classified as conjunctive for ECD and head direction if they met both the two-part criteria for ECD properties and the two-part criteria for head direction properties (i.e., conjunctive cells met a four part criterion). For analyses of individual cell data and population directional data, the Rayleigh test was used unless otherwise specified. For comparing two distributions, the circular statistics version of the ANOVA was first attempted (i.e., Watson-Williams test; Berens, 2009); however, the sample was too small for valid testing with ANOVA (though the result was identical), so the circular statistic equivalent to the Kruskal-Wallis test (multisample test for equal median directions; Fisher et al., 1993; Berens, 2009) was used and reported (i.e., for comparing conjunctive vs ECD-only distribution of mean vector directions).

To rule out the possibility that self-motion-related firing produced spurious ECD profiles, we also analyzed the data segments that were excluded for all other ECD analyses reported in this paper-the long, relatively still periods. Of the 60 cells with ECD properties, 18 had occupancy in at least $90 \%$ of the bins and were included in this analysis. These 18 cells were collected from two rats, 7 were conjunctive cells, and 11 were ECD-only cells.

\section{Self-motion and cross-covariance analyses}

Cells collected during sessions in which the rat did not run enough trials for complete coverage on the spatial or conjunctive plots (head direction $\times$ ECD; see below) were excluded from further analyses (30 additional cells were excluded from two sessions, so 339 putative pyramidal cells remained). Position and head direction data were used to map the spatial (next section) and self-motion reference frame for each cell and to cross-correlate cell activity with preferred self-motion states. For these analyses position data were interpolated and smoothed by convolution with a Hamming window that was $1 \mathrm{~s}$ long. For self-motion rate maps and cross-covariance analyses only, head direction data gaps $<1$ s were transformed using directional cosines for interpolation using the interp1 function in MATLAB, then transformed back to polar coordinates (Gumiaux et al., 2003). Next, head angular velocity, linear velocity, and firing rate were calculated for each video frame using a $100 \mathrm{~ms}$ sliding window. Finally, the occupancy and number of spikes for each $3 \mathrm{~cm} / \mathrm{s}$ by $20 \% \mathrm{~s}$ bin were calculated and converted to firing rate for each bin with $>0.5 \mathrm{~s}$ of occupancy (Chen et al., 1994a). For illustrative purposes (not cell classification analyses), the self-motion firing rate maps were smoothed by convolving with a Gaussian function for the $2 \times 2$ bins surrounding each bin (Whitlock et al., 2012). For all colormap plots (spatial and selfmotion), the colormap represented a range of firing rates from 0 (blue) to the maximum value indicated on the plot in maroon. No adjustments were made to the standard, evenly spaced colormap. Cells were classified as having a preferred self-motion state if the common points with sufficient occupancy (i.e., $>0.5 \mathrm{~s}$ ) from the self-motion maps for the first and second daily session (or split $1 / 2$ ) were significantly positively correlated $(p<0.01)$. This was generally the most conservative criterion for selfmotion cells of the three criteria reported by Whitlock et al. (2012). Since this is the only analysis for which we are using a one-part criterion and to be consistent with Whitlock et al. (2012), the more conservative $p$ value $(p \leq 0.01)$ was used here. Specifically, for each cell, to determine whether cells had "significant" self-motion properties, the map from the first daily behavioral session was shuffled, a correlation coefficient was computed between the first session (shuffled map) and the second session (unshuffled map), and this process was repeated 500 times. Then, the second behavioral session map was shuffled, the correlation coefficient was computed between the second session (shuffled map) and the first behavioral session (unshuffled map), and this process was repeated 500 times (total 1000 shuffles/cell). The entire shuffled dataset for each cell was used to calculate a critical $r$ value for the 99th percentile. Then, for each cell that had a significant preferred self-motion state (low linear velocity right turn, low linear velocity left turn, low linear velocity right or left turn, low linear and angular velocity, forward linear motion, forward right turn, and forward left turn; Chen et al., 1994a) a cross-covariance analysis was performed between the firing rate and the appropriate velocity component. Specifically, right turn cells were cross-correlated with head angular velocity, right and left turn and low velocity cells were cross-correlated with absolute head angular velocity, low velocity cells were also crosscorrelated with linear velocity (usually this correlation is negative suggesting deceleration tuning), forward-motion cells were cross-correlated with linear velocity, and forward-right cells were cross-correlated with linear and head angular velocity separately. Finally, the normalized crosscovariance was calculated for each maze segment that was at least $2 \times$ the window size. The normalization produced a range from -1 to 1 by dividing each value by the peak of individual velocity and firing rate autocorrelations. The cross-covariance was computed for each segment because each segment was broken by a brain-stimulation reward blackout period. Next, the segment cross-covariance values were normalized by multiplying by the proportion of total spikes for all valid segments (segment spikes/total spikes across all segments) and summed across all segments to generate one cross-covariance plot per behavioral session. This additional normalization step does not change the range of the data, it simply ensures that the contribution of the segment's cross-covariance plot is proportional to the number of spikes in that segment. In other words, segments with few spikes will not produce a spurious effect. The first and second behavioral sessions were combined for this analysis when both were available. For individual cell cross-covariance plots with head angular velocity, positive correlations indicate a right turn ( positive head angular velocity) while negative correlations indicate a left turn (negative head angular velocity). To determine whether peaks in the final cross-covariance plot were significant, spike data for each cell was jittered by a random amount $\pm 1.5 \mathrm{~s}$ (to disrupt any real cross-covariance relationships) then a new cross-covariance was computed and this process was repeated 1000 times. Jittered data for each cell were collapsed across all lags into a single large distribution, then the $95 \%$ confidence interval was calculated for this distribution. Negative or positive peaks that corresponded to self-motion properties for the cell and exceeded the confidence interval were considered significant. In the case of multiple peaks, the largest peak was used for determining the cross-covariance lag. Finally, cells that underwent the cross-covariance analysis were classified as active before motion ( peak $<-50 \mathrm{~ms}$ lag), active simultaneously with the onset of movement (peak within $\pm 50 \mathrm{~ms}$ lag 0; i.e., the size of the sliding window for smoothing), or active after movement ( peak $>50 \mathrm{~ms}$ lag). For illustrative purposes only, the cross-covariance plot for left turn cells was inverted (i.e., plotted as change from baseline). In addition, 
A
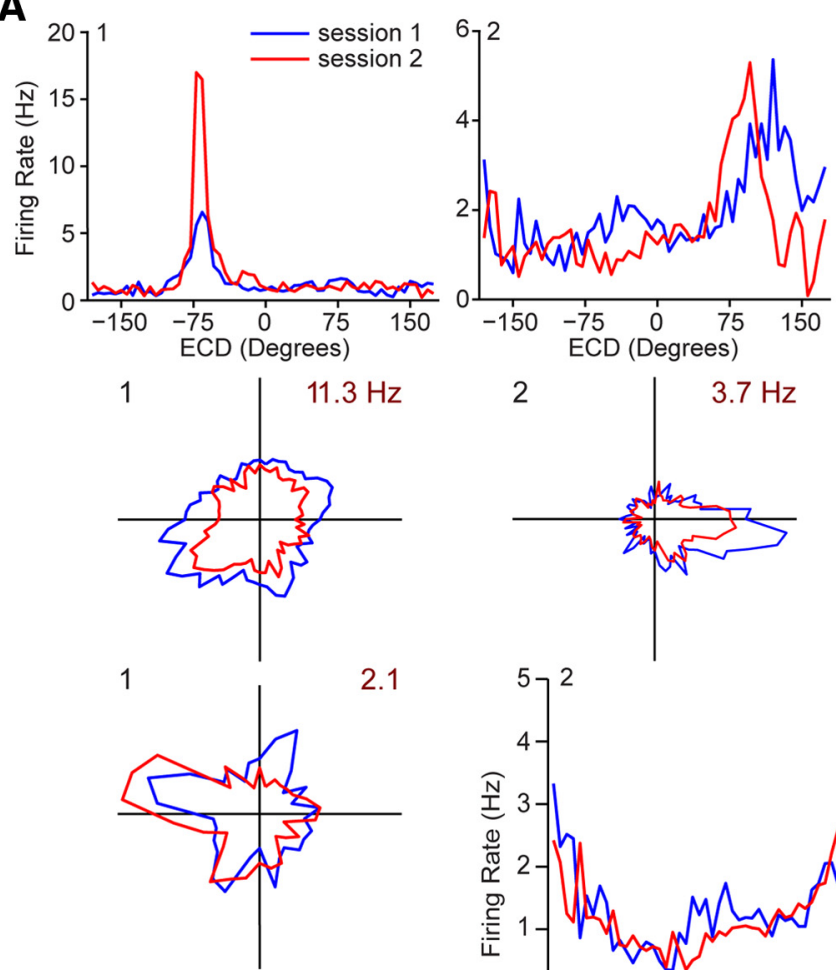
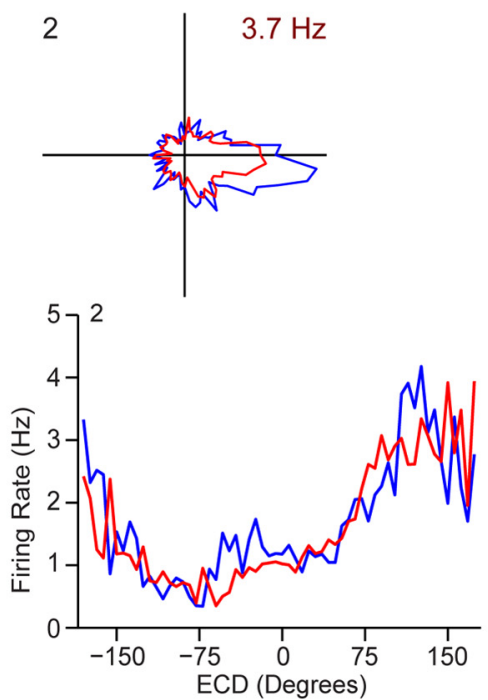

B
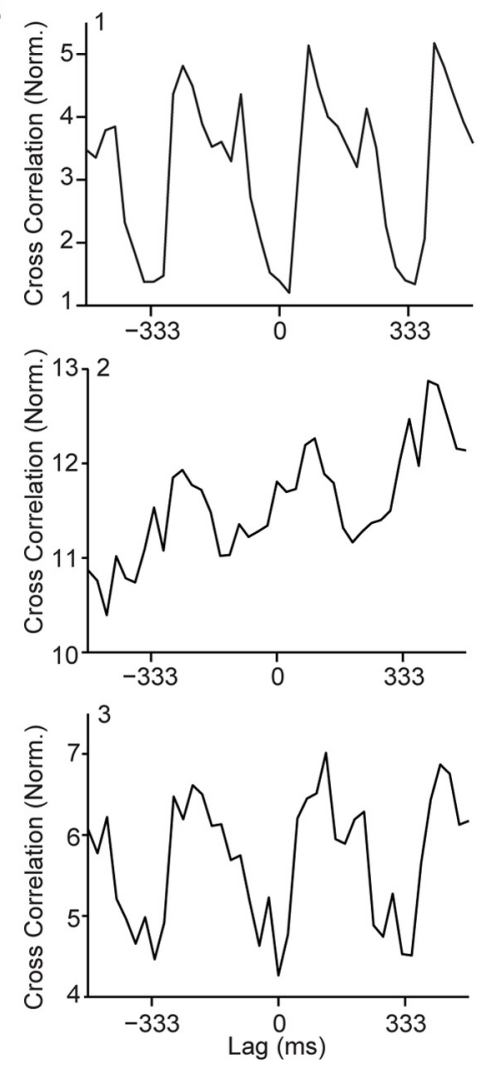

Figure 4. All cell types were required to be stable for inclusion and ECD cells are modulated by the blinking of the cue light. $A$, Top, Two ECD cells that met the two-part stability and Rayleigh criteria. Firing rate for ECD ( $6^{\circ}$ bins) for individual sessions. Cells were classified as having ECD properties if they had a significant Rayleigh test for unimodal deviation from a uniform distribution and were stable (change in mean vector direction $<7$ bins) across behavioral sessions. Middle, Two head direction cells that met the two-part stability and Rayleigh criteria. Firing rate for head direction ( $6^{\circ}$ bins) for individual sessions. Cells were classified as having head direction properties if they had a significant Rayleigh test and were stable (change in peak vector direction of $<7$ bins) across maze sessions. Bottom, Two conjunctive cells that met the four-part stability and Rayleigh criteria, i.e., conjunctive cells had to meet both the two-part ECD criteria and the two-part head direction criteria. Firing rate for head direction (left; polar plot; $12^{\circ}$ bins) and ECD (right; $6^{\circ}$ bins) for individual sessions. $B$, A substantially higher proportion of ECD cells were modulated by the blinking of the cue light (68\%) compared with cells that did not fall into any category $\left(18 \% ; \chi_{(1)}^{2}=34.6, p<0.0001\right)$. The actual proportion of cells with ECD properties modulated by the cue light is likely higher, since the modulation is probably linked to the cue direction receptive field. To have a large enough sample, cross-correlations are conducted for all times when the cue light is active, even when the cue is not in the ECD receptive field for the cell. Time stamps for the onset of each blink of the cue light (target) were cross-correlated with spike time stamps (reference). See Materials and Methods for a detailed description of the cross-correlation procedure and classification. We noticed that for both self-motion and ECD light-modulated cells sometimes light modulation was in phase and other times it was out of phase with the blinking of the light; however, we were unable to find any correspondence between this feature and any of the variables we assessed (e.g., anatomy, cell type).

population cross-covariance plots were constructed for conjunctive cells with self-motion properties that were active before movement and ECDonly cells with self-motion properties that were active after movement.

\section{Spatial profile firing rate maps and classification}

Occupancy and number of spikes were calculated for each spatial bin $(\sim 1.5 \times 1.5 \mathrm{~cm})$ and then converted to firing rate. Only bins with at least $0.2 \mathrm{~s}$ occupancy were included. For illustrative purposes only, occupancy and then firing rate maps were smoothed by convolving with a 2D Gaussian function (5 bin half-width).

\section{Conjunctive firing rate maps}

Occupancy and number of spikes were calculated for each $45^{\circ}$ of ECD by $45^{\circ}$ of head direction bin and converted to firing rate. These "conjunctive plots" were used to ensure that the head direction and ECD cells truly encoded a single reference frame and that conjunctive cells had a single preferred combination of cue and head direction and were not dual cells (i.e., did not have two bands of high activity, one for preferred head direction and another for preferred ECD).

Cross-correlations between light blink onset and spikes

For a subset of the data ( $n=208$ cells from two rats), time stamps were collected for the onset of each blink of the cue light $(3 \mathrm{~Hz}$ blink rate) for two consecutive behavioral sessions. For these data, crosscorrelations were constructed for all cells between time stamps for the onset of each blink of the cue light (reference) and spike time stamps (target). A cross-correlation was computed for each segment (end of brain-stimulation blackout period from the previous segment to the onset of brain stimulation for the current segment) and then normalized by the proportion of spikes in that segment. Then, normalized cross-correlations with a $1 \mathrm{~s}$ window $( \pm 500 \mathrm{~ms})$ and $25 \mathrm{~ms}$ bin size from all segments were summed to produce plots. The cue light was on for $166.6 \mathrm{~ms}$ then off for $166.6 \mathrm{~ms}$ to produce a $3 \mathrm{~Hz}$ (i.e., every 333 $\mathrm{ms}$ ) blink rate. Cells were scored blind to type by two separate scorers (a third scorer who was also blind to type broke disagreements) and were considered to be modulated by the blinking of the cue light if at least two of three reviewers agreed on the type. A cell was considered light modulated if scorers agreed that there were three distinct and evenly spaced peaks.

\section{Histology}

After the final recording session, rats were deeply anesthetized with Euthasol and transcardially perfused with $0.1 \mathrm{~m}$ PBS followed by $4 \%$ paraformaldehyde. The whole head was postfixed in $4 \%$ paraformaldehyde with electrodes in place for $24 \mathrm{~h}$, then brains were extracted and cryoprotected in $30 \%$ sucrose. Frozen sections were cut $(40 \mu \mathrm{m})$ using a sliding microtome or custom block-face imaging system (Leica vibratome), mounted on chrome alum-subbed slides, stained with cresyl echt violet, and imaged using a NanoZoomer Imaging system (Hamamatsu). 


\section{A}
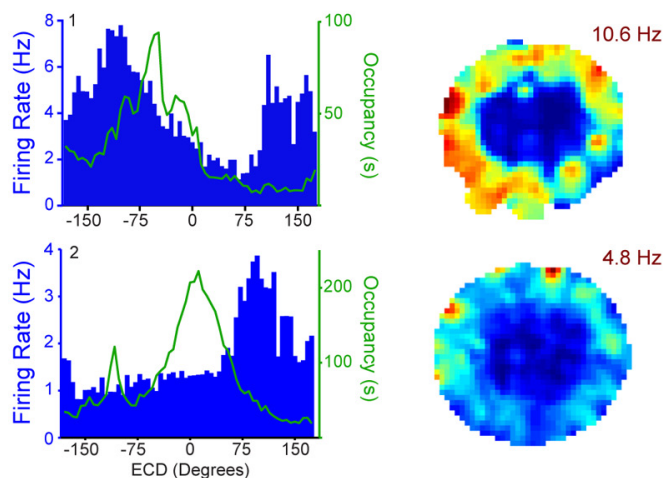

B
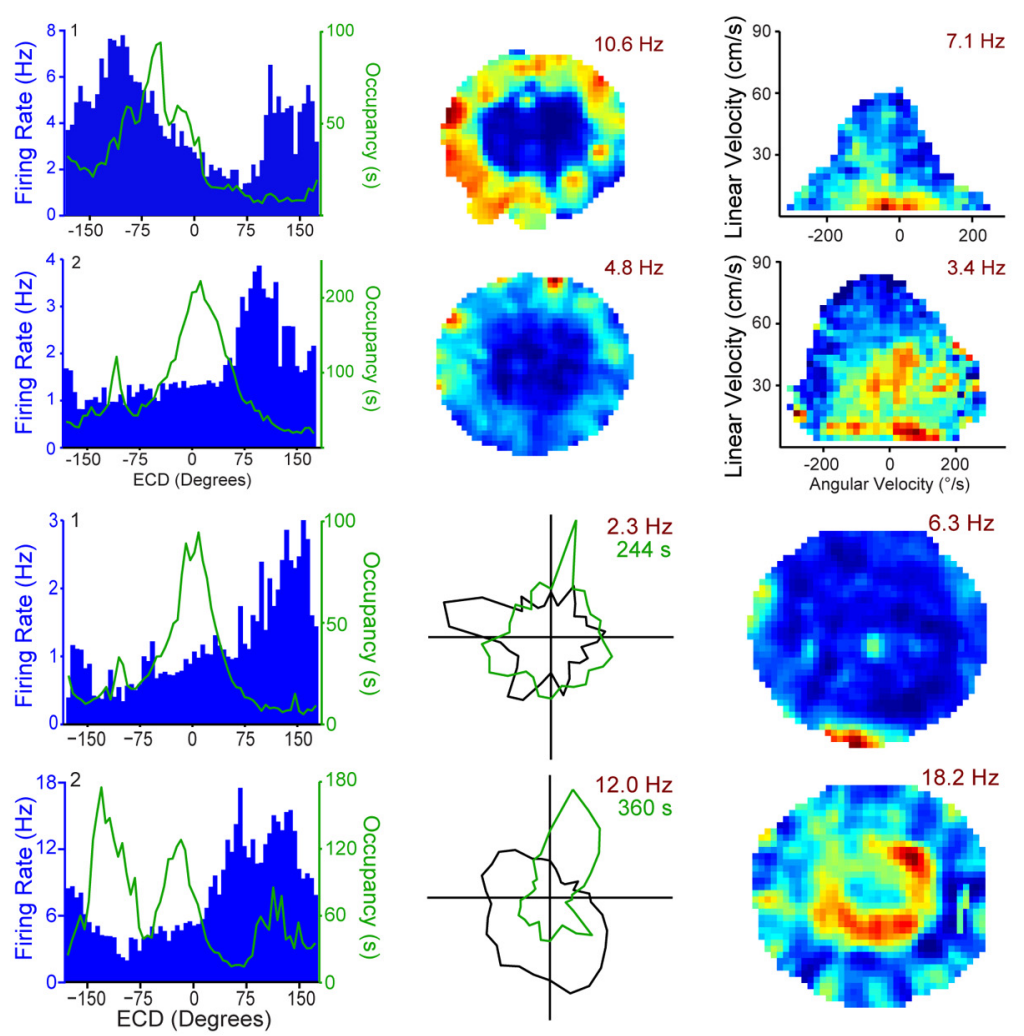

2
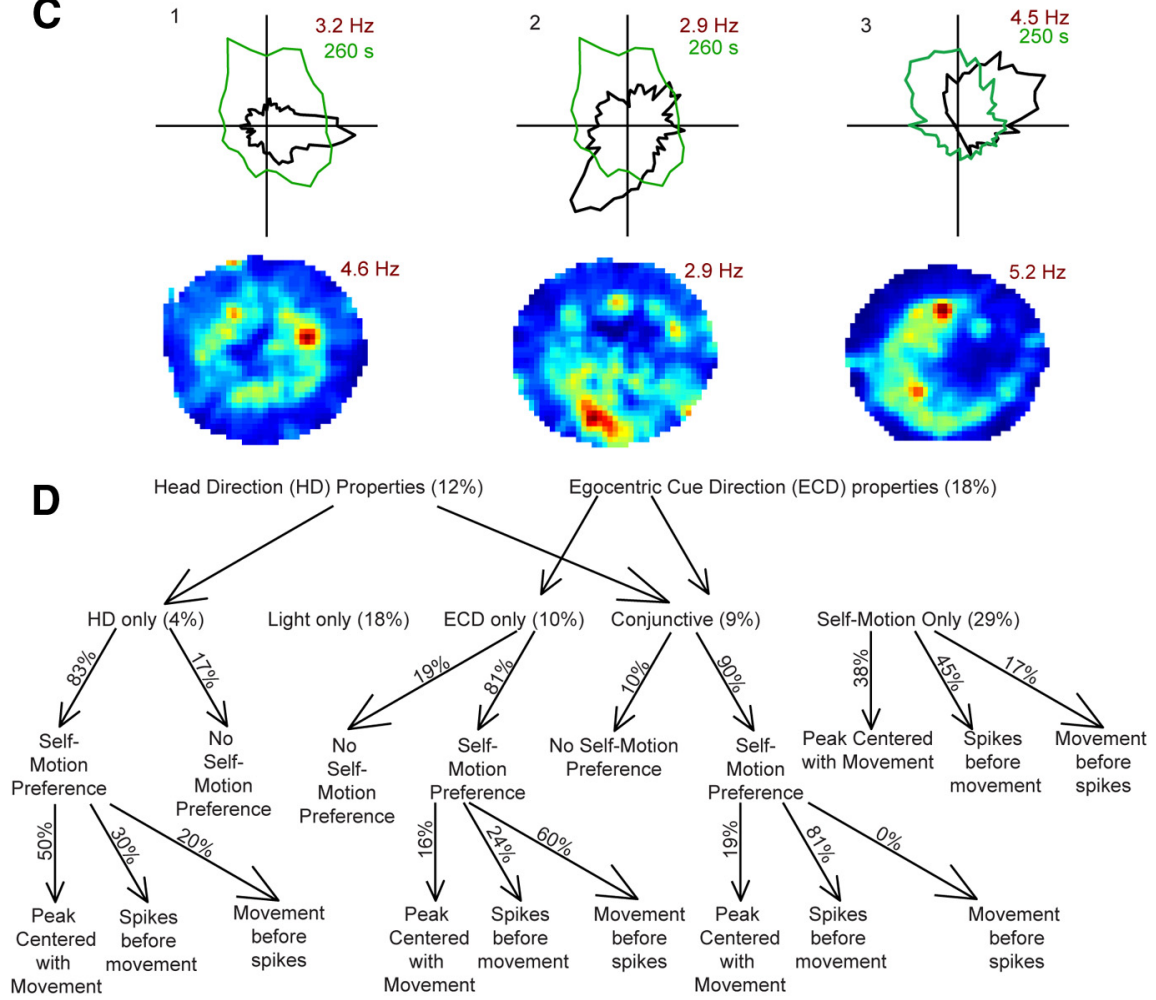

Figure 5. ECD, head direction, and conjunctive cells are active across the space of the maze, and occupancy does not account for the observed effects. $\boldsymbol{A}$, Left, Firing rate for ECDs (blue bars; $6^{\circ}$ bins) with occupancy (green line, s) overlaid. The negative ECDshifted occupancy is explained by the left turn preference of one rat. Middle, Smoothed spatial firing rate maps for the same cells. Note, the distinct spatial profile exhibited by many cells is likely explained by the relatively stereotyped nature of the task and the limited receptive field of cells with ECD properties. This appears to cause the cells to be active over a large but limited range of spatial locations. Right, Occupancy data and number of spikes are binned according to linear velocity (vertical axis) and head angular velocity (horizontal axis), then converted to firing rate. $\boldsymbol{B}$, Left, Firing rate for ECDs (blue bars; $6^{\circ}$ bins) with occupancy (green line, s) overlaid. Noncentered occupancy is explained by the tendency of one rat to sit for short periods at the end of each trial facing the previous zone (i.e., with the next cue light nearly behind the rat) during the earlier phases of training. Middle, Polar plots

\section{Results}

Posterior parietal neurons encode the egocentric position of light cues and these cells are modulated by the

\section{blinking of the cue light}

We recorded from 378 putatively unique PPC pyramidal cells from four rats of which 339 were sufficiently active during behavioral sessions for subsequent analysis (see Materials and Methods). Of these 339 cells, $18 \%$ encoded the ECD (60 cells; Fig. 3A). We used a stringent two-part criteria for classifying cells as ECD cells: (1) the Rayleigh test of directionality indicated that the cue position firing rate vector had a significant unimodal deviation from uniformity ( $p \leq 0.05$ ) and (2) the preferred cue direction was stable across behavioral sessions (Fig. $4 A$; change in mean vector direction $<7$ bins). Further, for a subset of the cells (including 41 of the 60 cells with ECD properties) we collected time stamps for the onset of each blink of the cue light. This allowed us to assess modulation of cells with ECD properties by the blinking of the cue light (Fig. $4 B$ ). We found that a substantially higher proportion of ECD cells was modulated by the blinking of the cue light $(68 \% ; 28$ cells) compared with cells that did not fall into any category $\left(18 \% ; 20\right.$ of 110 cells; $\chi_{(1)}^{2}=$ $34.6, p<0.0001)$. This suggests that ECDmodulated cells have properties of visual cortical cells with a limited receptive field. To our knowledge ECD cells have not been previously reported in rats.

Interestingly, cells with ECD tuning tended to fall into one of two apparent spatial categories: cells with ECD preferences closer to the periphery of the rat's visual field tended to be active on the periphery of the maze (Fig. $5 A \# 1-2$; $B$ \# 1), while cells with ECD tuning toward the nasal portion of the rats visual field tended to be active on the central

of firing rate for head direction (black line; $12^{\circ}$ bins) for the same cells. Occupancy (green line, s) is overlaid. Right, Smoothed spatial firing rate maps for the same cells. C, Top, Polar plots of firing rate for head direction (black line; $6^{\circ}$ bins) with occupancy (green line, s) overlaid. Bottom, Smoothed spatial firing rate maps for the same cells. $A-C$, For head direction plots and rate maps the peak firing rate is indicated in maroon. $\boldsymbol{D}$, Cell-type categories. Despite the stringent twopart criteria for most categories, a majority of the cells could be classified $(\sim 75 \%)$. Note that the number of cells is different for the first and second rows of this schematic because the analyses for some cell types further down the chart required more trials for sufficient occupancy and thus were conducted on a slightly smaller subset of cells. "Light only" cells showed cue light modulation but did not fall into any of the other cell types. 

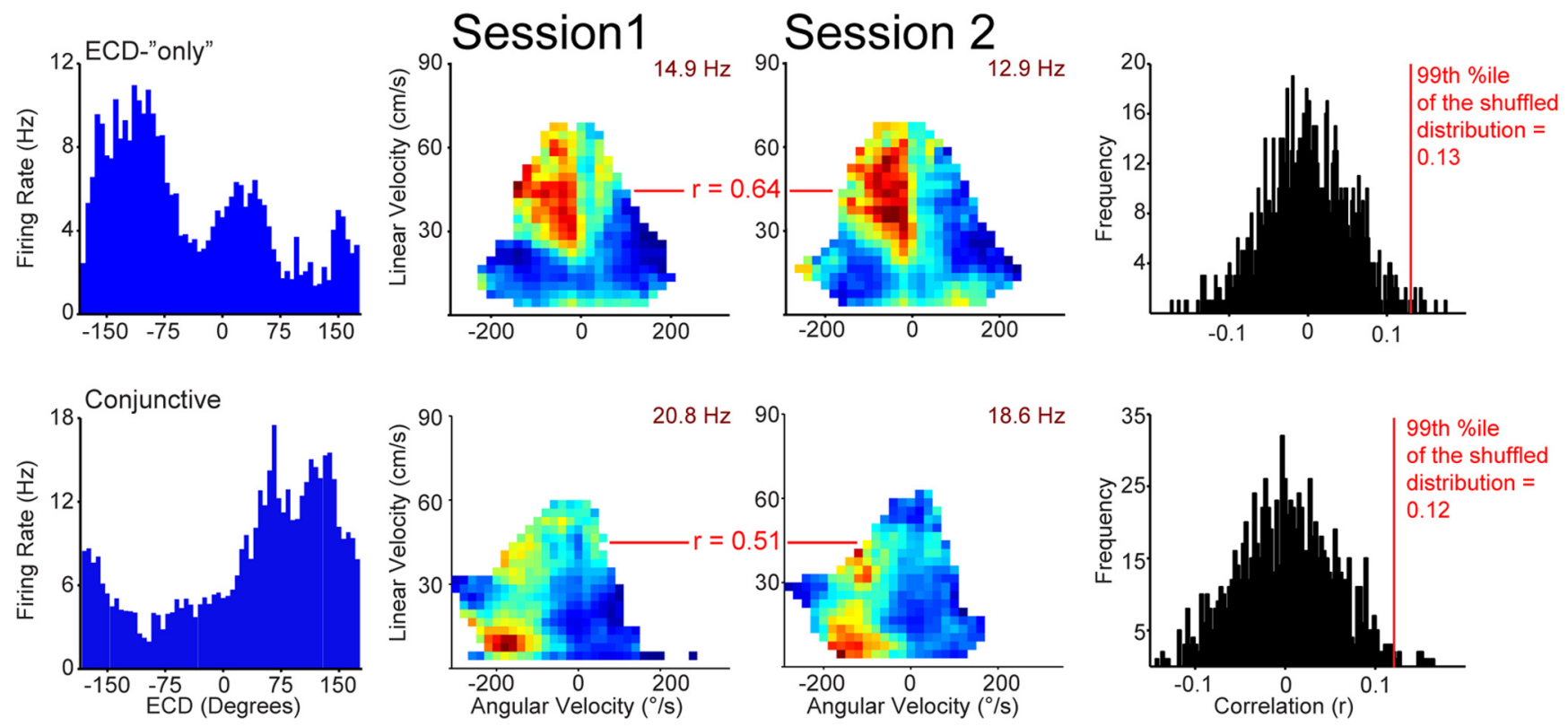

Figure 6. Most cells with ECD properties have a preferred orienting direction. Left column, ECD-only (top) and conjunctive (ECD $\times$ head direction; bottom) cell ECD plots (blue bars; firing rate $/ 6^{\circ}$ ECD). Middle two columns, Cells were classified as having a preferred self-motion state if the self-motion maps for two behavioral sessions were significantly positively correlated (99th percentile of random shuffled distribution). Self-motion maps from two behavioral sessions and corresponding correlation values are shown for one example cell from each functional type category. Occupancy data and number of spikes are binned according to linear velocity (vertical axis) and head angular velocity (horizontal axis; positive head angular velocity corresponds to a right turn), then converted to firing rate. Note, motion modulation and ECD encoding are sometimes apparent as two distinct peaks in ECD plots. For example, the ECD-only cell (top) has two peaks, one on the left (presumably the ECD receptive field for this cell) and a second peak in the middle (likely from the straight, forward linear motion-related activity). The cue light would be in front of the rat during forward motion and would create a second false ECD peak near $0^{\circ}$. Right column, The shuffled distribution and critical $r$ value corresponding to the 99 th percentile is shown for each example cell. For each cell, the map from the first behavioral session was shuffled 500 times and a correlation coefficient was computed between the shuffled and unshuffled maps. Then, this process was repeated to shuffle the map for the second session 500 times (total 1000 shuffles/cell) to calculate a critical $r$ value for the 99 th percentile $(p<0.01)$. See Materials and Methods for additional details.

portion of the maze (Fig. 5B\#2). This spatial and ECD pattern could suggest that some cells are specialized for setting trajectories (spatially peripheral cells), while other cells are specialized for adjusting trajectories mid route (spatially central cells). However, after looking into this issue more closely we became convinced that the more parsimonious explanation is that the spatial profile is a product of the relatively stereotyped nature of the task and the limited receptive field of cells with ECD properties. In other words, cells with peripheral receptive fields are more likely to be active at the periphery of the maze because the cue light tends to be in the peripheral visual field when the rat is in this large but limited range of spatial locations. Thus, the distinct spatial profile is likely determined by the ECD tuning of the cell.

Finally, we assessed the firing rate of cells as a function of allocentric head direction. Similar to previous studies (Chen et al., 1994a), we found that $12 \%$ of PPC neurons met our two-part criteria for classification as head direction cells (Fig. $3 B)$ : (1) they fired at a significantly higher rate for a particular heading (e.g., North; $p \leq 0.05$ ) and (2) were stable across behavioral sessions (change in mean vector direction $<7$ bins; Fig. 4A). To distinguish clearly the type of data being displayed, whenever possible, ECD-only data are plotted as blue bars and head direction-only data are plotted as polar plots throughout this paper. Our task allowed for good sampling of all possible head directions and all head direction cells were active across large portions of the apparatus (Fig. 5C).

Posterior parietal neurons encode the conjunction of a specific head direction and ECD

The foregoing results demonstrate that the rat PPC contains neurons sensitive to the egocentric relationship between the animals head and the cue light (ECD cells) as well as neurons sensitive to allocentric directional heading in the environment (head direction cells). We additionally observed many cells that met both head direction tuning and ECD tuning criteria. Therefore, we classified cells with both above criterion head direction properties and above-criterion ECD properties as conjunctive cells ( $9 \%$ of all cells; ECD $\times$ head direction; Figs. $3 C, 5 D)$. Plotting the ECD and head direction tuning as a rate map for all possible combinations of ECD and head direction confirmed our two-part Rayleigh and stability criteria-based classification (Fig. 3). The conjunctive cell classification was only reliable when there was sufficient coverage of both variables, so the conjunctive cell classification was performed for a subset of the data with sufficient coverage (e.g., $>1$ s occupancy for each combination of ECD and head direction; $n=$ 309 cells). Visual inspection of the conjunctive plots revealed that all cells conjunctive for ECD and head direction preferred a specific combination of cue and head direction (single hot spot; Fig. 3C; 29 cells). In other words, none of the conjunctive cells appeared to be dual cells (i.e., had two intersecting bands). In contrast to conjunctive cells, which had a single hot spot on conjunctive plots, when head direction-only units (12 cells; $4 \%$ of all cells) or ECD-only units (32 cells; 10\%) were plotted in this way, they had a single band along the appropriate dimension (Fig. 3A,B).

Conjunctive cell activity anticipates movement toward the cue while ECD-only cells simply reflect the current position of the cue

Impaired spatial orientation following PPC lesions (Kolb et al., 1994) suggests that ECD cells in the PPC may signal required 
A
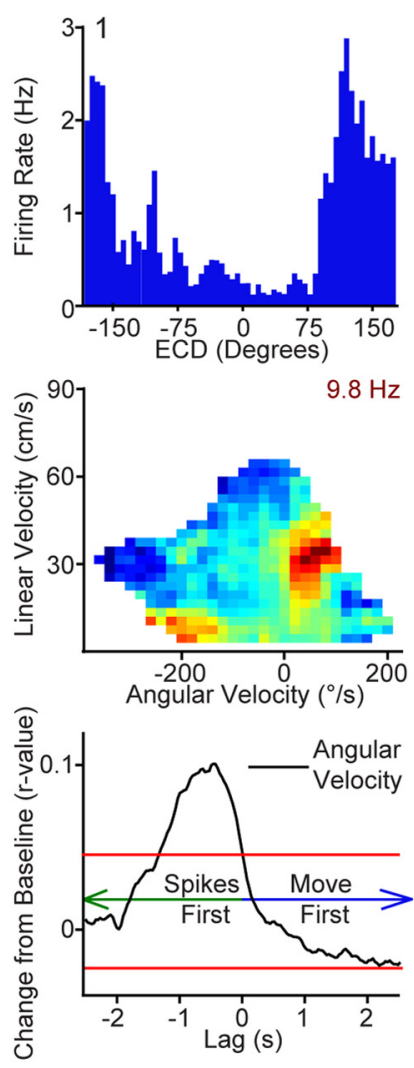

C

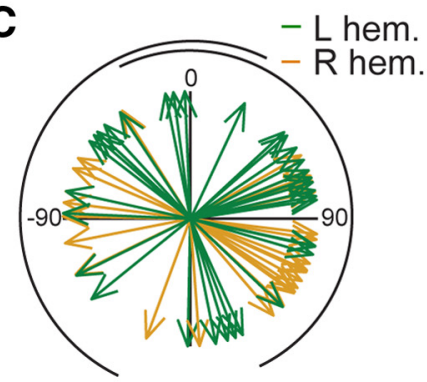

Conjunctive
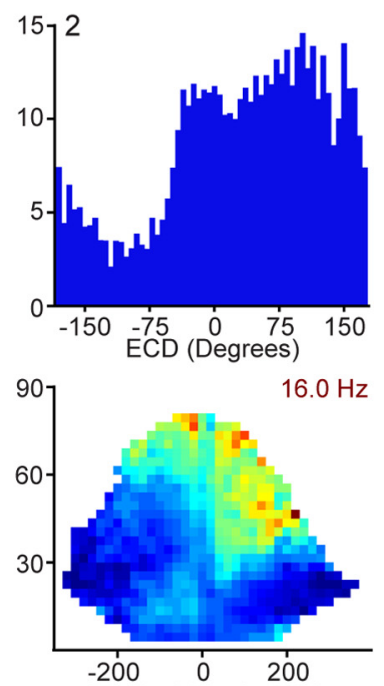

Angular Velocity $(\% / s)$
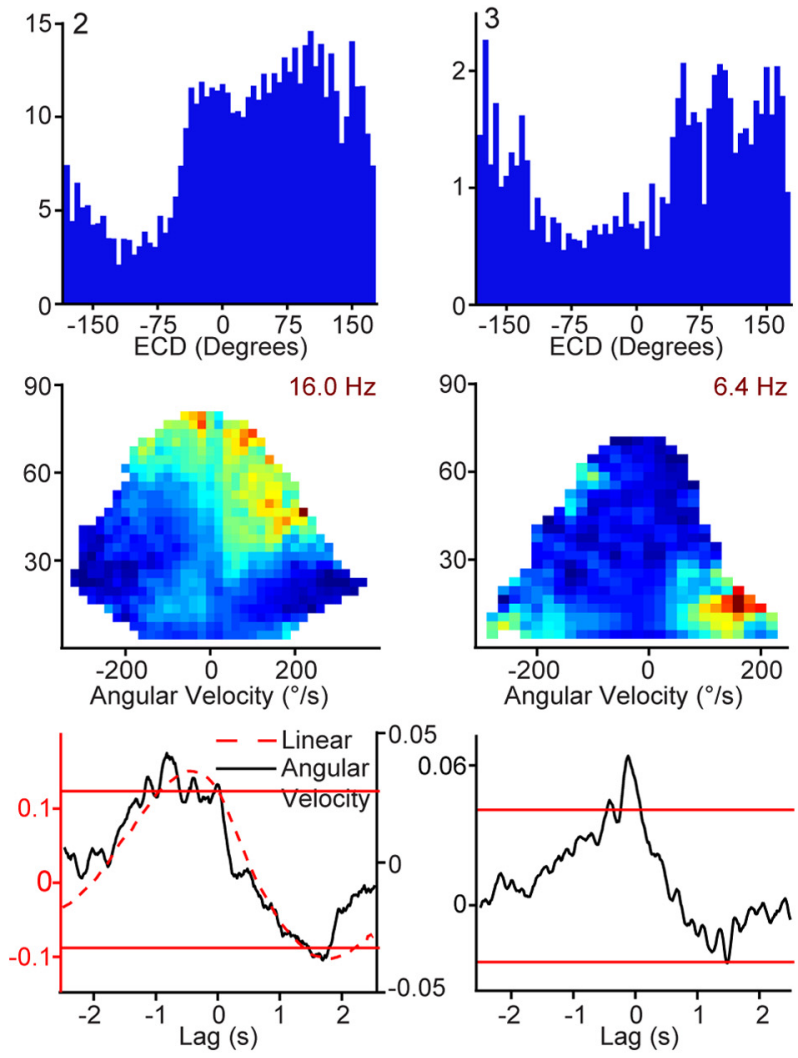

Angular Velocity $(\% / s)$

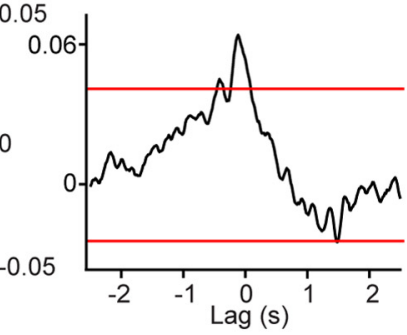

B ECD Only
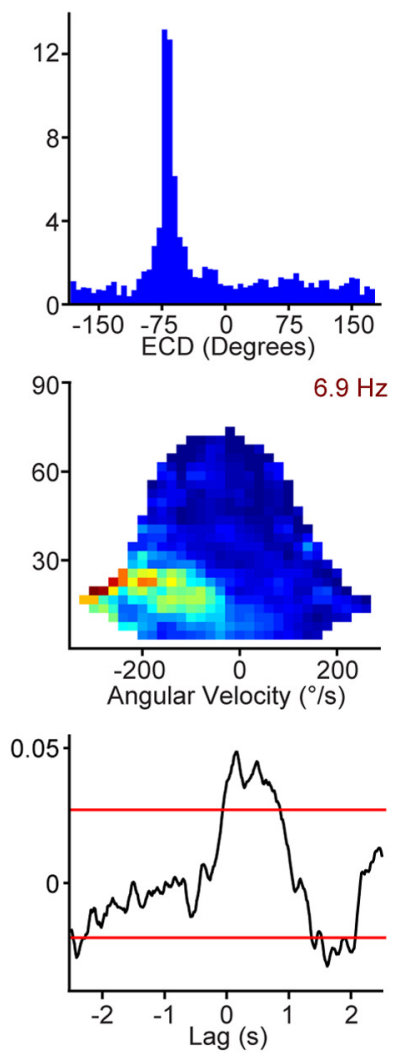

Population Data

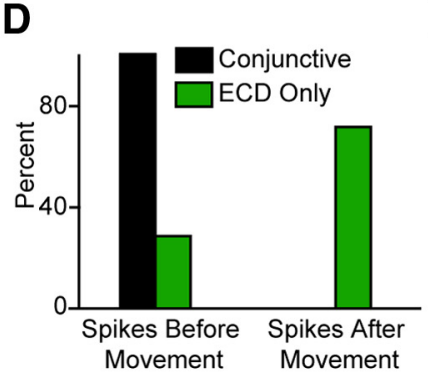

E
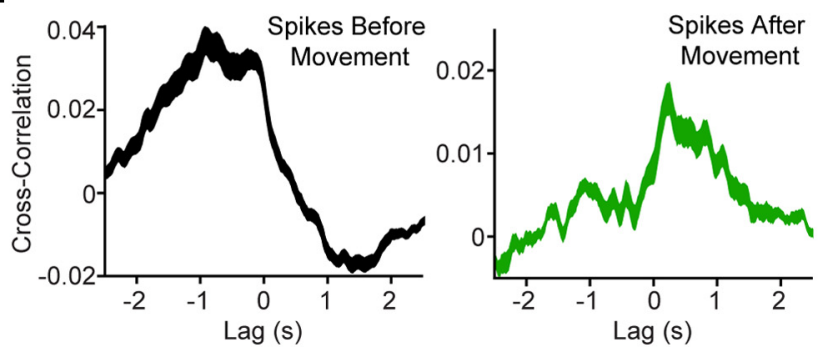

Figure 7. Conjunctive cell activity anticipates movement toward the cue while ECD-only cells reflect the current position of the cue. $\boldsymbol{A}$, Examples of three conjunctive cells illustrating that conjunctive cells typically anticipate movement with either long latency (nearly $1 \mathrm{~s}$, left and middle columns) or short latency (175 ms; right column). Top, Firing rate for ECDs (blue bars; $6^{\circ}$ bins). Middle, Occupancy data and number of spikes are binned according to linear velocity (vertical axis) and head angular velocity (horizontal axis), then converted to firing rate. Max firing rate ranges from 0 (dark blue) to the peak value indicated in maroon. Bottom, Cross-covariance between preferred self-motion (e.g., for a right turn cell like 1 or 3 firing rate was cross-correlated with angular velocity) and cell activity revealed that conjunctive cells anticipate movement. Red horizontal lines denote the $95 \%$ confidence interval for head angular velocity (not linear velocity) for the same cells. The confidence intervals were generated from jittering spike times a random amount between $\pm 1.5 \mathrm{~s}$, calculating the cross-covariance, repeating this process 1000 times, then collapsing across lags for the complete shuffled cross-covariance dataset and calculating the $95 \%$ confidence interval. $\boldsymbol{B}$, Most ECD-only cells show the opposite pattern, turning precedes activity, suggesting turning into the ECD receptive field. $C$, Tuning for the population of cells with ECD properties is distributed to the sides of the rat (mean vector $=91^{\circ}, p \leq 0.01$; left hemisphere green; right hemisphere orange). Black semicircles indicate approximate rat visual field (Adams and Forrester, 1968). Note, some cells with tuning toward the periphery of the visual field wrap to the opposite visual field so that the mean tuning direction is behind the rat and outside of the visual field (e.g., $\boldsymbol{A} \# 3$ and Fig. $3 A$ \# 2). $\boldsymbol{D}$, Population data are consistent with examples shown in $\boldsymbol{A}$ and $\boldsymbol{B}$. A significantly higher proportion of conjunctive cells were active before movement than ECD-only cells $\left(\chi_{(1)}^{2}=21.3, p<0.0001\right)$. $\boldsymbol{E}$, Mean ( \pm SEM; shaded) cross-covariance for conjunctive cells that were active before movement (black; left) and ECD-only cells that were active after movement (green; middle). The population data confirms the single-cell examples illustrating that the population of conjunctive cells anticipates movement with either short or long latency (apparent as two bumps on the population plot at approximately - $1 \mathrm{~s}$ and $-175 \mathrm{~ms}$ ) while turning tends to precede activity for ECD-only cells with short latency.

changes in spatial orientation when the landmark is not directly in front of the rat. Supporting this notion, we found that many cells have a preferred orienting direction (Fig. 6) and the population tuning for ECD was distributed nonuniformly to the sides of the rat (mean vector $=91^{\circ}, p \leq 0.01$ ) with a tendency to cluster toward the central visual fields of each eye (Fig. 7C; Adams and
Forrester, 1968). Given this observation, we hypothesized that the PPC might have a role in the online control of goal-directed navigation. To address this possibility, we determined whether PPC cells had a preferred orienting direction (e.g., right turn) by plotting firing rate as a function of the rat's current linear and angular velocity (i.e., self-motion rate maps; Chen et al., 1994a; 


\section{A}
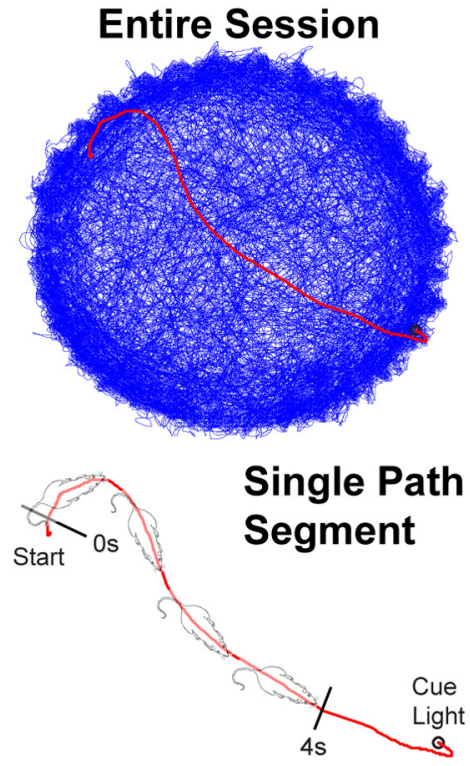

Single Path Segment

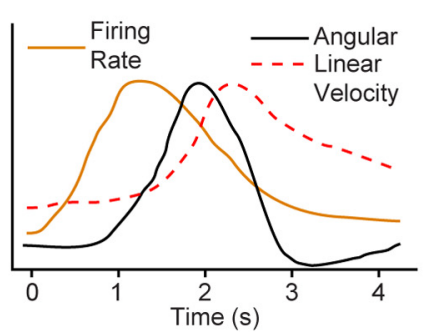

B
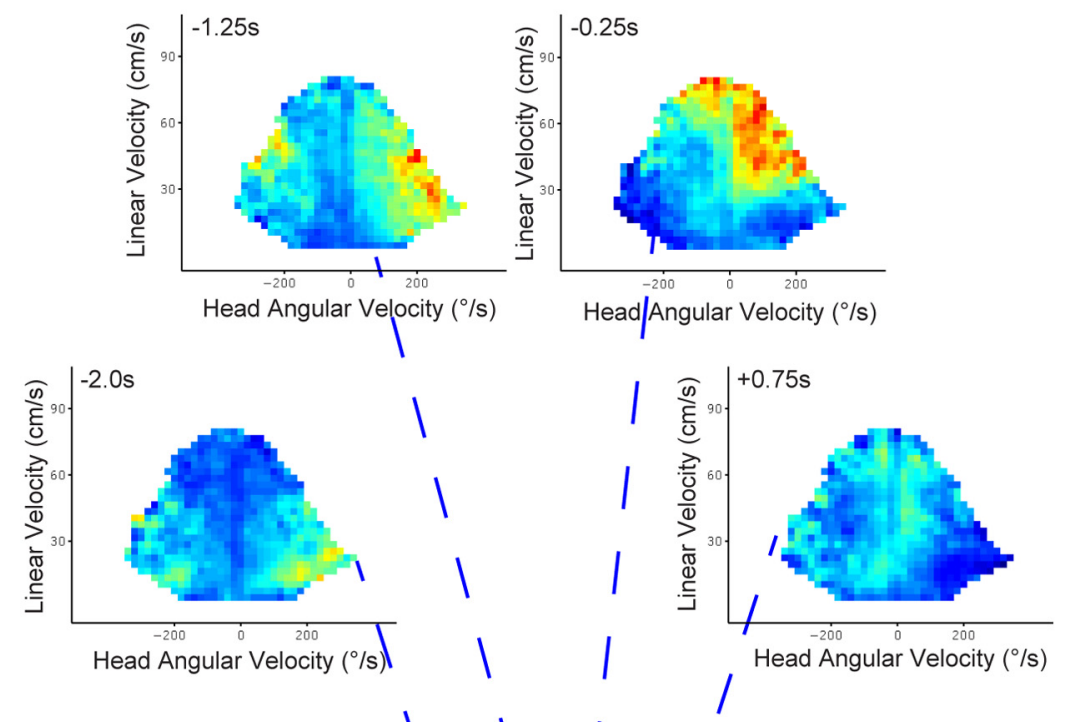
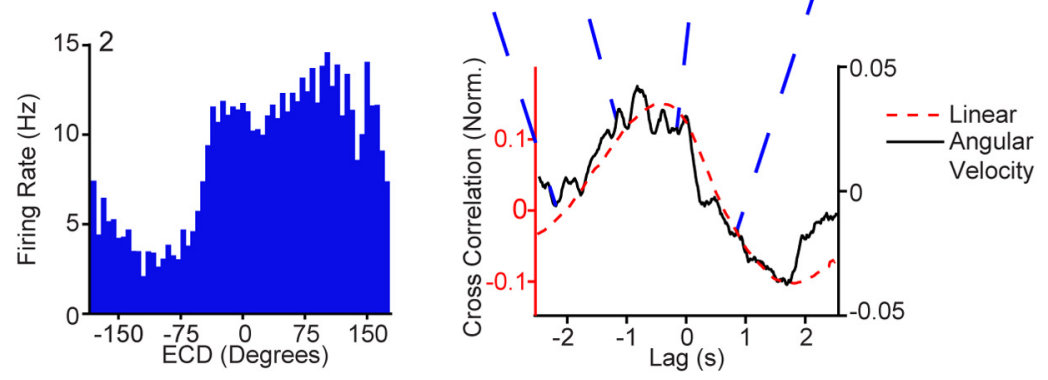

Figure 8. Conjunctive cells anticipate movement. $\boldsymbol{A}$, Top, Path plot for a real day session (blue line). Middle, Single segment from the real complete path plot (also shown in red on complete path plot) from the session shown (top). Bottom, Hypothetical temporal relationship between firing rate, angular velocity, and linear velocity from a single segment where the behavior of the animal produced the conjunctive cue position and head direction necessary to activate this cell. If this pattern were repeated on other segments the cross-covariance plot for all segments shown in $B$ would result. If there were no anticipation all three peaks would be aligned or the firing rate peak would follow peaks in velocity. $\boldsymbol{B}$, Conjunctive cell 2 from Figure $7 A$, left. Firing rate for ECDs (blue bars; $6^{\circ}$ bins). Right, Cross-covariance between preferred self-motion (i.e., left turn and forward linear velocity) and cell activity revealed that this conjunctive cell anticipates right turn movement and also anticipates linear movement. Top, To illustrate the cross-covariance, data shown in a time shift analysis was performed on the self-motion rate map. By shifting the spike time stamps by lags shown at the top of each frame $(-2,-1.25,-0.25$, and $+0.75 \mathrm{~s})$ it is possible to illustrate the angular then linear anticipation for this cell. For each frame occupancy, data and number of spikes are binned according to linear velocity (vertical axis) and head angular velocity (horizontal axis) and then converted to firing rate for the spike's data, which are time shifted by the lag listed at the top of the frame. Firing rate ranges from zero (dark blue) to $14 \mathrm{~Hz}$ (maroon). For illustrative purposes the self-motion firing rate maps were smoothed by convolving with a Gaussian function for the $2 \times$ 2 bins surrounding each bin in the $x$ and $y$, but not the $z$ (time) dimension.

Whitlock et al., 2012). Cells were classified as having a preferred self-motion state if the self-motion rate maps for two behavioral sessions were significantly positively correlated (Fig. 6; 99th percentile from randomly shuffled maps). For cells with a preferred self-motion state, we performed a cross-covariance between the cell's preferred self-motion (e.g., right turn) and firing rate, which allowed us to determine whether cell activity preceded, followed, or occurred simultaneously with the preferred motion (Fig. 7). The preferred self-motion state of a cell that met our self-motion criteria was defined based on the location of the peak firing rate on the self-motion rate map (as described previously: Chen et al., 1994a). For example, cell 1 on Figure $7 B$ "preferred" left turns, so the cross-covariance was performed for head angular velocity (not linear velocity) and cell activity. For this cell there was a negative correlation with a peak at approximately $+125 \mathrm{~ms}$, indicating that left turns tended to follow cell activity (note for illustrative purposes the cross-covariance plots are displayed as change from baseline, i.e., inverted on Fig. 7). Cross-covariance plots were determined to have a significant peak if the largest peak corresponding to the preferred self-motion state exceeded the $95 \%$ confidence interval for a spike-jittered dataset for the same cell.
Most cells conjunctive for head direction and ECD had a preferred self-motion state $(90 \% ; 26$ cells) and every cell with a preferred self-motion state had a significant peak that corresponded to the preferred self-motion state (i.e., exceeded $95 \%$ confidence interval). Spikes preceded movement for $81 \%$ of cells with a preferred self-motion state $(21$ cells; Fig. $7 A$ ). For the remaining cells, the peak in cell activity coincided with the onset of movement. This suggests that a majority of the conjunctive cells may provide information that is used by the motor system to set or correct trajectories toward a goal (Fig. 8).

Conjunctive cells with anticipatory activity tend to fall into one of two categories: long (nearly 1 s) or short latency $(\sim 175$ $\mathrm{ms}$ ) anticipatory activity. These two groups are apparent as two bumps on the population plot (Fig. $7 E$ ). Given that there is a stereotyped component to the task, it seemed possible that the long latency anticipatory activity might be a product of the rat performing a consistent orienting response (i.e., the rat always orients toward the cue light after it falls in the ECD receptive field, so firing always "anticipates" movement). Thus, we examined the activity of ECD-only neurons to determine whether these cells also showed long latency anticipatory activity. 

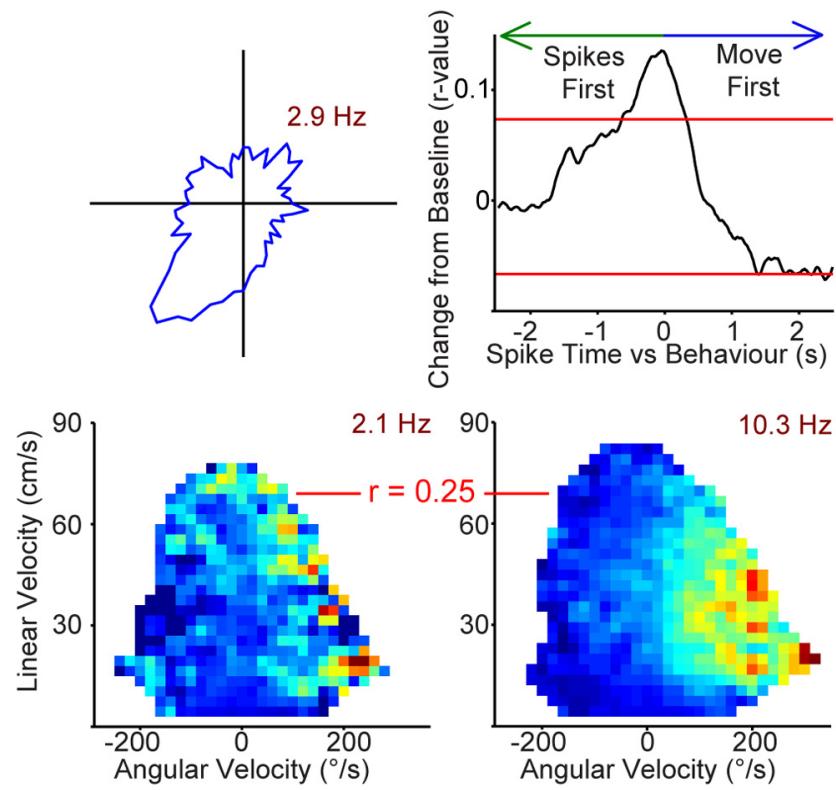

Figure 9. Most head direction-only cells also encode angular velocity (83\%) and some anticipate movement. Top left, Polar plot (blue line; firing rate $/ 6^{\circ}$ head direction) for one example cell that is motion modulated. Bottom, 0 ccupancy data and number of spikes are binned according to linear velocity (vertical axis) and head angular velocity (horizontal axis; positive head angular velocity corresponds to a right turn), then converted to firing rate. Cells were classified as having a preferred self-motion state if the self-motion maps for two behavioral sessions were significantly positively correlated (99th percentile of random shuffled distribution). Self-motion maps from two behavioral sessions and corresponding correlation values are shown for this example cell. Max firing rate is in maroon text. Top right, Some of the turn $\times$ head direction cells, including this example, also anticipate movement (30\%). Cross-covariance between preferred self-motion and cell activity revealed that this head direction-only cell anticipates right turns. This cell had a right turn preferred self-motion state so angular velocity was used. The positive correlation before time 0 indicates anticipation of a right turn by $\sim 125 \mathrm{~ms}$. Red horizontal lines denote the $95 \%$ confidence interval calculated from spike-jittered data for this same cell.

Many ECD-only cells (i.e., did not also have head direction properties) had a preferred self-motion state (26 cells; $81 \%$ of ECD-only cells; Fig. 6) and nearly all of these cells had a significant cross-covariance peak (25 cells); however, the crosscovariance pattern for ECD-only cells was dramatically different from those of conjunctive cells. Only 6 cells (24\% of ECD-only cells) were active before movement toward the cue light, while 15 cells $(60 \%)$ were active after turning (presumably into the cue light receptive field; Fig. $7 B$ ) and for the remaining 4 cells (16\%) activity coincided with the onset of movement. Thus, if only the cells with peaks in activity before or after the onset of movement are considered (21 conjunctive cells and 21 ECD-only cells), the proportion of conjunctive cells with activity before movement (100\%) was significantly larger than ECD-only cells (29\%; 6 cells; Fig. $\left.7 D ; \chi_{(1)}^{2}=21.3, p<0.0001\right)$. The population data for ECDonly cells that follow movement (Fig. $7 E$ ). Note the amplitude of the population activity for the ECD-only cells is dramatically less than for conjunctive cells, which is not surprising if ECD-only cell activity signals the current position of the cue light and is not tightly coupled with behavior as with conjunctive cells (i.e., if activity follows movement because ECD cells are active after the rat turns into the receptive field). The dramatic difference in anticipatory activity between ECD and conjunctive cells suggests that ECD-only cells may be critical for locating the cue light and conjunctive cells may be critical for orienting the rat.
The identical pattern is observed if only pairs of randomly selected cells collected from the same session are considered $(n=$ 10 cells). Thus, if all variables except cell activity are equivalent the effect is preserved (for the paired cells analysis $100 \%$ of conjunctive cells are active before movement vs $20 \%$ of ECD-only cells; $\left.\chi_{(1)}^{2}=6.7, p<0.01\right)$. Finally, movement anticipation is a unique feature of cells conjunctive for ECD and head direction. ECD-only and conjunctive head direction by ECD cell populations is not different in other measures. For example, an equivalent proportion of ECD-only cells $(65 \%)$ and conjunctive cells $(72 \%)$ are light modulated $\left(\chi_{(1)}^{2}=0.23, p=0.63\right)$, and the tuning of the population of ECD-only and conjunctive cells is not different $(p=0.52)$.

Most head direction-only cells also encoded angular velocity Some cells did not meet the ECD criteria and appeared to encode only for head direction on the conjunctive plots; therefore, we performed the self-motion and cross-covariance analyses on these head direction-only cells. Most of the head direction-only cells (10 cells of 12 head direction-only cells; $83 \%$ ) had a selfmotion preference. All of these cells had an angular self-motion preference (none had a linear preference). This suggests that these cells are conjunctive for head direction and angular velocity, similar to what has been described previously in the PPC (Chen et al., 1994a). Next, we performed the cross-covariance analysis on the cells with an angular self-motion preference and found that all cells with significant self-motion properties also had a significant peak in the cross-covariance plot (exceeded 95\% confidence interval of jittered distribution). For these cells five had a peak centered at zero, while spikes occurred before movement for three cells, and movement occurred before spikes for the remaining two cells (Fig. 9). For the three cells that anticipated movement, the anticipatory lag was variable: $125 \mathrm{~ms}$, $500 \mathrm{~ms}$, and $1 \mathrm{~s}$. Similar conjunctive head direction by selfmotion cells have been reported in the dorsal tegmental nucleus (Sharp et al., 2001b).

\section{Self-motion-only cells either anticipate movement or are} active simultaneously with movement onset

Finally, we assessed self-motion preferences of the cells that did not fall into the ECD-only, head direction-only, or conjunctive categories and found that $29 \%$ of all recorded cells (90 of 309 cells) were self-motion-only cells, described previously (Fig. 10; McNaughton et al., 1994; Whitlock et al., 2012). Two putative self-motion-only cells did not have a significant cross-covariance peak. For the remaining 88 self-motion-only cells fired either before the onset of movement ( 40 cells; $45 \%$ ) or simultaneously with the onset of movement (33 cells; 38\%). Whitlock et al. (2012) found that self-motion cells tended to anticipate movement when rats performed an autonomous task and fired simultaneously with movement when rats performed a stereotyped task. Given that our task is a mixture of stereotyped and autonomous, our finding of a mixture of these two cross-covariance cell types in the same task is consistent with this previous report. Interestingly, nearly all of the self-motion-only cells that anticipated movement in the present study did so on a short timescale (73\%; 29 of 40 cells; $<250 \mathrm{~ms}$ and the rest anticipated with lags $<500 \mathrm{~ms}$ ). This suggests that the long latency (up to $1 \mathrm{~s}$ ) anticipating self-motion cells reported by Whitlock et al. (2012) may have actually been conjunctive ECD $\times$ head direction cells under the appropriate task conditions. 
A
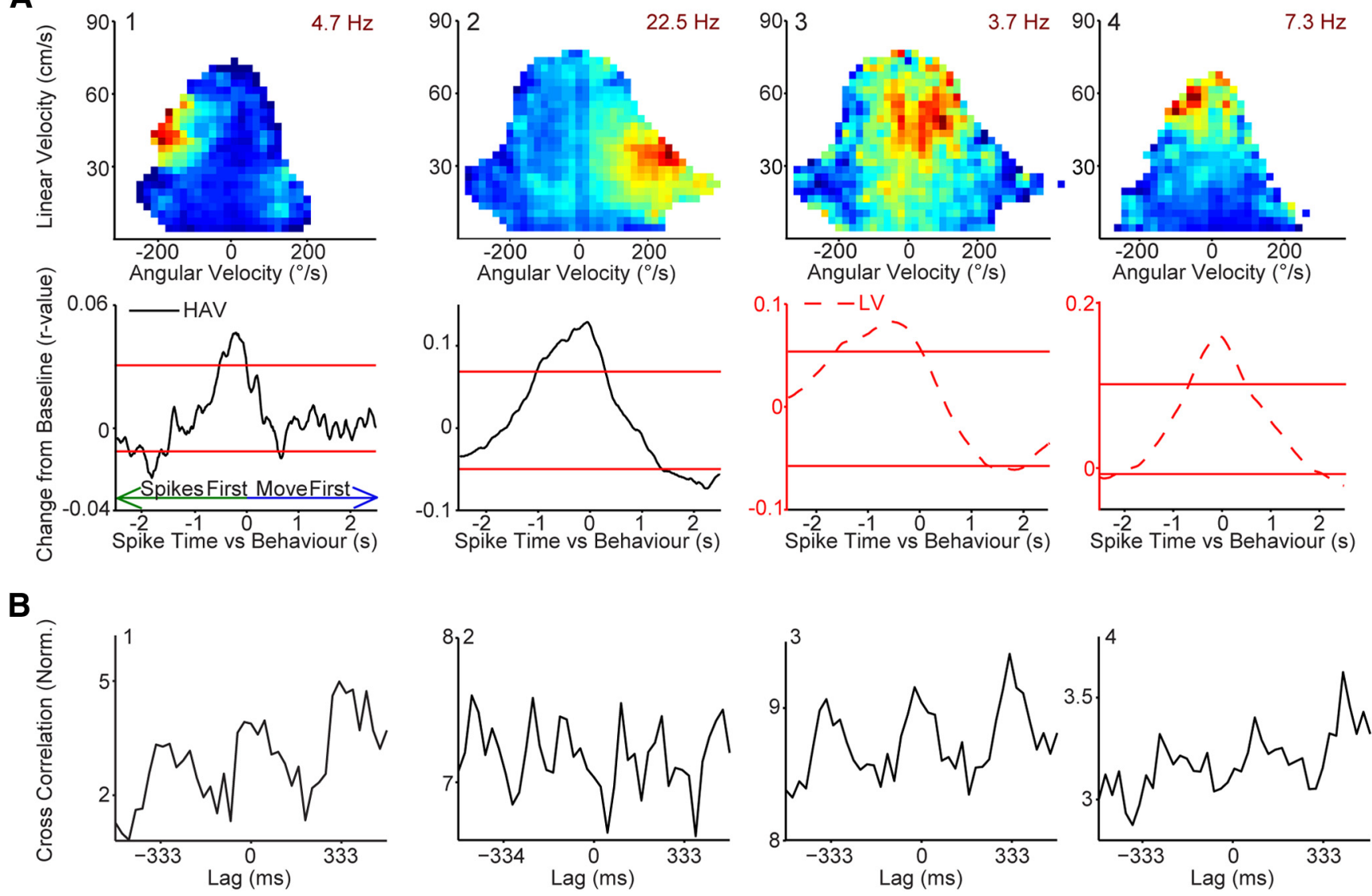

Figure 10. Self-motion-only cells are also modulated by the blinking of the cue light, suggesting that optic flow may be at least partially responsible for the activity of these cells. A, Four examples of self-motion-only cells (no cue or head direction properties) are shown. Top, Occupancy data and number of spikes are binned according to linear velocity (vertical axis) and head angular velocity (horizontal axis; positive head angular velocity corresponds to a right turn), then converted to firing rate. Cells were classified as having a preferred self-motion state if the self-motion maps for two behavioral sessions were significantly positively correlated (99th percentile of shuffled distribution). Max firing rate is in maroon. Bottom, Self-motion cells tended to be active either before the onset of movement (45\%; e.g., columns 1-3) or simultaneously with the onset of movement (38\%; e.g., column 4). Cross-covariance between preferred self-motion (e.g., for a forward motion cell like 3 , linear velocity) and cell activity. HAV, head angular velocity; LV, linear velocity. Red horizontal lines denote the $95 \%$ confidence interval calculated from spike time-jittered cross-covariances for the same cell. $\boldsymbol{B}$, Some cells with self-motion-only properties (31\%) were modulated by the blinking of the cue light. This suggests that optic flow may be at least partially responsible for the activity of these cells. Four examples are shown of light-modulated, self-motion-only cells. We noticed that for both self-motion and ECD light-modulated cells (Fig. 4), sometimes light modulation is in phase and other times it is out of phase with the blinking of the light; however, we were unable to find any correspondence between this feature and any of the variables we assessed (e.g., anatomy, cell type).

Cue light blink modulation in self-motion-only cells suggests that activity in these cells may be driven at least in part by visual input such as optic flow

Next, we assessed modulation by the blinking of the cue light for self-motion-only and head direction-only cells. Surprisingly, a higher proportion of self-motion-only cells were modulated by the blinking of the cue light $(33 \%)$ compared with cells that did not fall into any category $\left(18 \% ; \chi_{(1)}^{2}=4.4, p<0.05\right.$; Fig. 10). A significantly smaller proportion of self-motion-only cells was modulated by the blinking of the cue light than cells with ECD properties $\left(\chi_{(1)}^{2}=11.9, p<0.001\right)$. Interestingly, some head direction-only cells were also modulated by the blinking of the cue light (five cells) and each of these cells also had self-motion properties. The modulation of cells with self-motion properties by the blinking of the cue light suggests that some of the selfmotion cells may derive their motion related firing at least in part from optic flow.

Finally, functional cell types are intermingled across the surface and depth of the PPC (Fig. 11). The only exception is that head direction preferences may be organized in columns since similar head direction tuning was often recorded on the same tetrode at multiple depths (consistent with previous reports; Chen et al., 1994a; Harvey et al., 2012). This intermixed anatomical arrangement suggests that inputs to PPC are not segregated (e.g., vestibular inputs to anterior PPC and visual inputs to posterior PPC). However, the intermixed anatomical arrangement is consistent with the idea that conjunctive cells are a combination of ECD-only and head direction-only cells (Figs. $1 A, D$ ) since intermixed cell types would be conducive to such a wiring arrangement.

\section{Discussion}

The results show that the PPC is tuned to both allocentric and egocentric reference frames. Two functional types of cells with ECD properties are described: cells that are conjunctive for ECD and head direction, which may be specialized for driving the execution of the appropriate behavioral response, and cells that have only ECD properties, which simply reflect the current egocentric position of the cue. This suggests that we have identified a specific cell type that may be responsible for the impaired orienting toward a goal that is observed following PPC lesions (Kolb et al., 1994; Save and Poucet, 2000). Our findings are consistent with the role of the PPC for spatially orienting to establish trajec- 

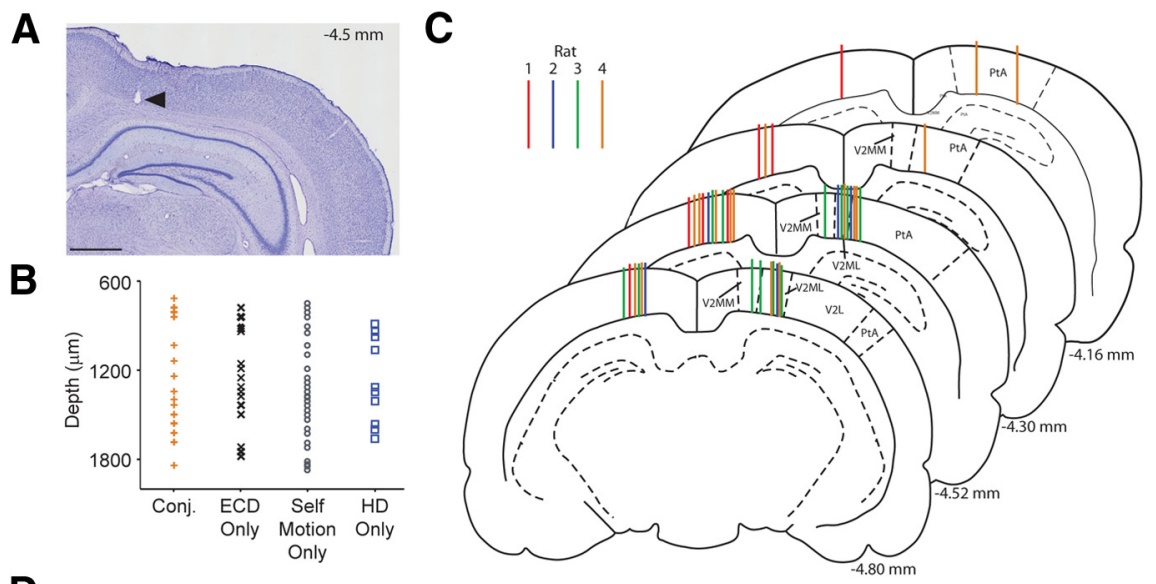

D

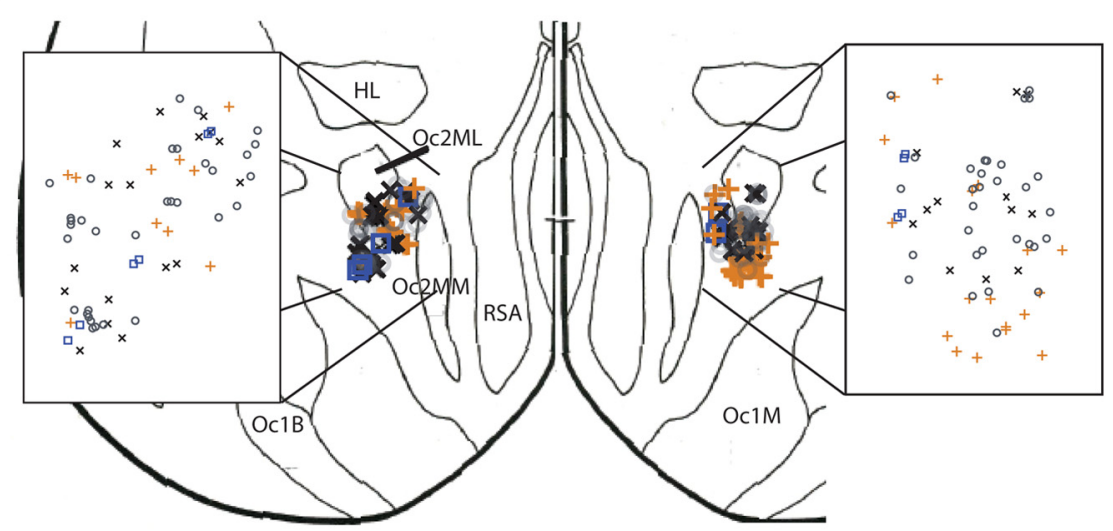

Figure 11. Electrode and cell-type placement. $\boldsymbol{A}$, Nissl-stained coronal sections showing the marking lesion from a tetrode in rat 3 (black arrowhead). This tetrode tract is an example of the most medial tetrode placement and demonstrates that recordings did not encroach on the retrosplenial cortex. Scale bar, $1 \mathrm{~mm}$. B, Approximate tetrode depth (micrometers) from cortical surface at time of recording for conjunctive (Conj.; orange + ), ECD-only (black x), self-motion-only (gray $\bigcirc$ ) cells, and head direction-only (HD) cells (blue $\square$ ). C, Coronal sections throughout the anterior (top) to posterior (bottom) extent of the rat PPC (Paxinos and Watson, 1998) color coded by rat (7 tracts for rat 1 in red, 5 tracts for rat 2 in blue, 11 tracts for rat 3 in green, and 16 tracts for rat 4 in orange). Each tract indicates the profile for a tetrode that recorded at least one putative pyramidal cell in the PPC during the random lights task. Distance posterior to bregma is listed for each slice (lower right). V2L, secondary visual cortex, lateral area; V2ML, mediolateral area; V2MM, mediomedial area; PtA, parietal association cortex. D, Placement of conjunctive (orange + ), ECD-only (black x), self-motion-only (gray $\bigcirc$ ), and head direction-only (blue $\square$ ) cells shown on a surface view in the horizontal plane (outlines indicate the $95 \%$ confidence interval for each region; adapted from Zilles, 1985). Inset shows magnified region of recording locations from the right hemisphere and demonstrates that functional cell types are not segregated into different anatomical regions. 0c2MM, occipital cortex, area 2, mediomedial part; 0c2ML, occipital cortex, area 2, mediolateral part; $0 \mathrm{c} 2 \mathrm{~L}$, occipital cortex, area 2, lateral part; 0c1M, occipital cortex, area 1, monocular part; RSA, agranular retrosplenial cortex; $\mathrm{HL}$, hindlimb area.

tories to a goal; however, our results also suggest that the PPC may contribute to adjusting the trajectory while the rat is in motion (Fig. $7 A$ \# 2). Interestingly, only the cells that are tightly coupled with the orienting response are also tuned to the world-centered reference frame. Thus, integration of egocentric and allocentric information may be critical for guiding normal goal directed locomotion.

The PPC may be part of a larger circuit that transforms from egocentric coordinates to allocentric coordinates for landmark-based navigation. Previous reports have suggested that some self-motion tuned cells in PPC have long latency $(\sim 1 s)$ anticipatory activity; however, no explanation was offered for the surprisingly long latency anticipation (Whitlock et al., 2012). Here we propose a possible explanation for this long latency anticipatory activity. Conjunctive cells with long latency anticipatory activity are consistent with a role for the PPC in performing the initial translation from egocentric to allocentric coordinates as part of a larger circuit for landmark-based navigation. This large circuit may be linked closely with behavior but on a longer timescale (Fig. 7A \# 1 and first "bump" approximately $-1 \mathrm{~s}$ in the population data). Therefore, the conjunctive representations of ECD and head direction may support network-based coordinate transformations to ultimately produce the landmark vector cells that have been observed in rodent hippocampus (including the present paradigm; Fig. 2; Deshmukh and Knierim, 2013), similar cells could allow animals to remember the position of a goal relative to the same landmark for vector-based trajectory computation by a variety of methods (O'Keefe and Nadel, 1978; Collett et al., 1986; Cheng, 1988; Etienne and Jeffery, 2004; Etienne et al., 2004; McNaughton et al., 2006; Gibson and McGowan, 2014).

The model for network-based coordinate transformation predicts that the population of conjunctive cue and head direction information is integrated to produce on-line representations of allocentric landmark position, then combined with distance information to produce landmark vector cells (i.e., gain fields for allocentric landmark position and distance; McNaughton et al., 1995). Therefore, we looked for cells encoding allocentric landmark position and distance to the goal in the PPC and found a very small number of cells that may encode in these reference frames; however, they were not reliable enough to make a claim. Alternatively, such cells may exist downstream of the PPC. One route for such information transfer to the hippocampus may be the retrosplenial cortex, which receives dense projections from the PPC (Reep et al., 1994), and projects to the entorhinal cortex (Vogt and Miller, 1983; Jones and Witter, 2007). Thus, allocentric landmark position may be integrated and combined with distance information in the retrosplenial cortex, entorhinal cortex, or hippocampus. Alternatively, distance information may exist in the PPC but in a different form that would be difficult to assess with our task. It is possible that the route modulated cells in PPC described previously (Nitz, 2012) may convey information about distance traveled from a landmark (e.g., start location) along a route.

The anticipatory activity observed in self-motion cells may represent part of this same circuit. It is interesting to speculate that, since some of our cell types appear to be prospectively encoding subsequent behavior with varying latencies, under certain conditions, we may see sequences of cell activity, similar to previous reports (Harvey et al., 2012). For example, it may be that ECD-only cells inform the position of the cue light, then conjunctive cells anticipate orienting toward the goal, and finally selfmotion cells anticipate completion of the orienting response and onset of acceleration toward the target. Thus, the self-motion cells may represent a final translation from egocentric coordinates to self-motion-based coordinates. 
A potential concern is that given the stereotyped nature of our task and the specific self-motion modulation of cells in PPC it is important to be cautious when interpreting response patterns, including ECD properties of cells. For example, if the rat always turned to the right when a cue light was in the same egocentric cue position, this could produce a spurious ECD response profile. However, such spurious effects are not driving the ECD responses we observed, because of the following reasons. (1) Our criteria for ECD cells are stringent; cells must have a significant Rayleigh and be stable across maze sessions. (2) The tuning width of some ECD cells is very narrow (Figs. $3 A \# 1,7 B$ ). (3) Each cue light position was chosen at random from 31 possible positions; therefore, it is unlikely that a cue light would be in the same position when the rat executed the specific behavior. (4) Some ECD plots have a second peak that corresponds to the motion modulation, which is distinct from the larger ECD peak (e.g., ECD-only cell on Fig. 6 has a large ECD peak at - 140 and a small self-motion peak near zero corresponding to the high linear velocity self-motion preference of this cell; see also Fig. 7A \# 2). (5) It is difficult to conceptualize how some self-motion states could produce spurious ECD tuning, for example, deceleration tuned ECD cells (Fig. 4B \# 1-2). (6) ECD cells are significantly more likely than self-motion-only cells to be modulated by the blinking of the cue light. (7) Finally, all ECD data shown in the paper excluded long relatively still periods, and if we generate ECD plots for these long relatively still periods, ECD encoding remains unchanged (mean shift in ECD tuning $\pm \mathrm{SD}=7.7^{\circ} \pm 5.3^{\circ}$; range $=0.5^{\circ}-16.3^{\circ}$; Fig. 12 ).

The primate PPC has also been conceptualized to be part of a circuit that transforms signals from different sensory modalities for motor planning and action (Xing and Andersen, 2000). The short latency anticipatory activity for conjunctive cells is consistent with this theory (Fig. 7A \# 3 and second "bump" at lag -175 $\mathrm{ms}$ in the conjunctive cell population data on E). Thus, the PPC may integrate current sensory information (e.g., visual position of a target) for translation into a behavioral orienting response. While limitations in rodent eye movements $\left(3-10^{\circ}\right.$ for eye movements that are not accompanied by head movements as part of a coherent orienting response; Meier and Dieringer, 1993; Wallace et al., 2013) limit the scope of studies in rodents, our data does suggest that the egocentric cue position cells we described here may be analogous to the retinal $\times$ eye position gain fields that have been described in nonhuman primates (Robinson et al., 1978). Modeling studies suggest to the retinal $\times$ eye position gain fields would be well suited for coordinate transformation to execute targeted reaching in primates (Zipser and Andersen, 1988; Salinas and Abbott, 1995). It is interesting to speculate that a motion-based reference frame (self-motion cells that also anticipate movement), may be the final step in these coordinate transformations in the rodent (McNaughton et al., 1994; Whitlock et al., 2012). Advances in recording, imaging, and virtual reality systems for rodents and in recording and imaging from freely moving primates should enable future studies to examine these initial findings in greater detail so that similarities and differences between rodents and primates can be better understood.

Analogous to the conjunctive ECD and head direction cells described here, representations of conjunctive combinations of current head direction and head angular velocity for continuous updating of head direction have been described in rodents (Skaggs et al., 1995; Sharp et al., 2001a; McNaughton et al., 2006). Similarly, eye-head, eye-world, and eye-hand centered gain fields have been reported in nonhuman primates, which may be involved in the coordinate transformation necessary for locating
Moving Only
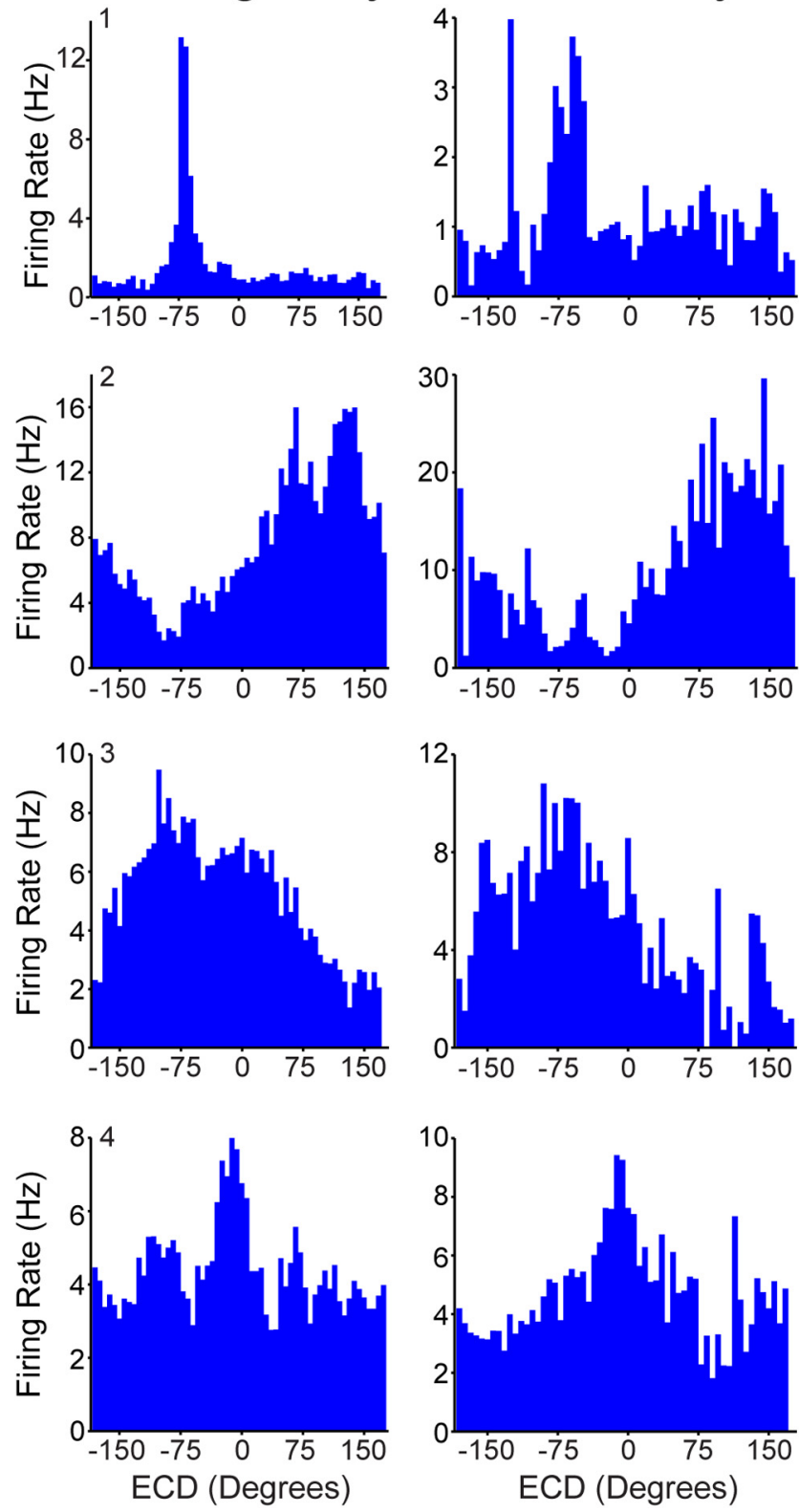

Figure 12. ECD cells are not an artifact of motion-related firing. Firing rate for ECDs (blue bars; $6^{\circ}$ bins) for four example cells with ECD properties. For ECD plots long relatively motionless periods were removed to prevent the influence of a confounding variable while the cue light remained in a similar position (left). However, since most cells with ECD properties are also modulated by specific motion states and our task has a stereotyped component, this suggested a possible confound. Specifically, the cells preferred self-motion state might tend to occur when the cue light was in the same position. In addition to the points described in the Discussion, to further rule out the possibility that self-motion-related firing produced spurious ECD profiles, we analyzed the data segments we had previously excluded, the long relatively still periods. Of the 60 cells with ECD properties 18 had occupancy in at least $90 \%$ of the bins for this still-only analysis. These 18 cells were collected from two rats, 7 were conjunctive cells, and 11 were ECD-only cells. Removing periods of movement had no effect on the ECD profiles (right). Further, the mean ECD (i.e., tuning) for the firing rate vector for all 18 cells that were included in this analysis was essentially identical for still only versus moving only data $7.7^{\circ} \pm 5.3^{\circ}$ (mean shift in $\mathrm{ECD}$ tuning $\pm \mathrm{SD}$; range $=0.5^{\circ}$ to $\left.16.3^{\circ}\right)$.

and reaching or orienting to targets (Andersen et al., 1985; Xing and Andersen, 2000; Bremner and Andersen, 2012). Current data suggest that the primate system may be more specialized for orienting the eyes, head, and limbs in reference to the head, body, 
and world (Andersen et al., 1985; Xing and Andersen, 2000; Hay and Redon, 2006; Byrne and Crawford, 2010; Bremner and Andersen, 2012), while the rat system may be more specialized for mapping route progression and orienting the body for navigation through space (Kolb et al., 1994; Nitz, 2006, 2012; Whitlock et al., 2012). This suggests a functional specialization in the primate evolution (but see, Sato et al., 2006; Vass and Epstein, 2013). However, it remains to be seen if there is truly a large distinction in PPC function or if experimental conditions and research focus have concealed similarities and artificially widened the gap.

\section{References}

Adams AD, Forrester JM (1968) The projection on the rats visual field on the cerebral cortex. Q J Exp Physiol 53:327-336. Medline

Andersen RA, Essick GK, Siegel RM (1985) Encoding of spatial location by posterior parietal neurons. Science 230:456-458. CrossRef Medline

Berens P (2009) CircStat: a MATLAB toolbox for circular statistics. J Stat Softw 31:1-21.

Bower MR, Euston DR, McNaughton BL (2005) Sequential-contextdependent hippocampal activity is not necessary to learn sequences with repeated elements. J Neurosci 25:1313-1323. CrossRef Medline

Bremner LR, Andersen RA (2012) Coding of the reach vector in parietal area 5d. Neuron 75:342-351. CrossRef Medline

Byrne PA, Crawford JD (2010) Cue reliability and a landmark stability heuristic determine relative weighting between egocentric and allocentric visual information in memory-guided reach. J Neurophysiol 103:30543069. CrossRef Medline

Calton JL, Taube JS (2009) Where am I and how will I get there from here? A role for posterior parietal cortex in the integration of spatial information and route planning. Neurobiol Learn Mem 91:186-196. CrossRef Medline

Chen LL, Lin LH, Green EJ, Barnes CA, McNaughton BL (1994a) Headdirection cells in the rat posterior cortex I. Anatomical distribution and behavioral modulation. Exp Brain Res 101:8-23. CrossRef Medline

Chen LL, Lin L-H, Green EJ, Barnes CA, McNaughton BL (1994b) Headdirection cells in the rat posterior cortex II. Anatomical distribution and behavioral modulation. Exp Brain Res 101:24-34. CrossRef Medline

Cheng K (1988) Some psychophysics of the pigeon's use of landmarks. J Comp Physiol A 162:815-826. CrossRef Medline

Collett TS, Cartwright BA, Smith BA (1986) Landmark learning and visuospatial memories in gerbils. J Comp Physiol A 158:835-851. CrossRef Medline

Connors BW, Gutnick MJ (1990) Intrinsic firing patterns of diverse neocortical neurons. Trends Neurosci 13:99-104. CrossRef Medline

Deshmukh SS, Knierim JJ (2013) Influence of local objects on hippocampal representations: landmark vectors and memory. Hippocampus 23:253267. CrossRef Medline

Etienne AS, Jeffery KJ (2004) Path integration in mammals. Hippocampus 14:180-192. CrossRef Medline

Etienne AS, Maurer R, Boulens V, Levy A, Rowe T (2004) Resetting the path integrator: a basic condition for route-based navigation. J Exp Biol 207: 1491-1508. CrossRef Medline

Euston DR, McNaughton BL (2006) Apparent encoding of sequential context in rat medial prefrontal cortex is accounted for by behavioral variability. J Neurosci 26:13143-13155. CrossRef Medline

Euston DR, Tatsuno M, McNaughton BL (2007) Fast-forward playback of recent memory sequences in prefrontal cortex during sleep. Science 318 : 1147-1150. CrossRef Medline

Fisher N, Lewis T, Embleton B (1993) Statistical analysis of spherical data, revised edition. New York: Cambridge UP.

Foster TC, Castro CA, McNaughton BL (1989) Spatial selectivity of rat hippocampal neurons: dependence on preparedness for movement. Science 244:1580-1582. CrossRef Medline

Gallistel CR (1990) The organization of learning. Cambridge: Bradform Books/MIT

Gibson B, McGowan F (2014) Rats average entire vectors when navigating toward a hidden goal: a test of the vector sum model in rodents. Behav Processes 102:18-24. CrossRef Medline

Gothard KM, Skaggs WE, McNaughton BL (1996) Dynamics of mismatch correction in the hippocampal ensemble code for space: interaction be- tween path integration and environmental cues. J Neurosci 16:80278040. Medline

Gumiaux C, Gapais D, Brun JP (2003) Geostatistics applied to best-fit interpolation of orientation data. Tectonophysics 376:241-259. CrossRef

Harris KD, Henze DA, Csicsvari J, Hirase H, Buzsáki G (2000) Accuracy of tetrode spike separation as determined by simultaneous intracellular and extracellular measurements. J Neurophysiol 84:401-414. Medline

Harvey CD, Coen P, Tank DW (2012) Choice-specific sequences in parietal cortex during a virtual-navigation decision task. Nature 484:62-68. CrossRef Medline

Hay L, Redon C (2006) Response delay and spatial representation in pointing movements. Neurosci Lett 408:194-198. CrossRef Medline

Hofer SB, Ko H, Pichler B, Vogelstein J, Ros H, Zeng H, Lein E, Lesica NA, Mrsic-Flogel TD (2011) Differential connectivity and response dynamics of excitatory and inhibitory neurons in visual cortex. Nat Neurosci 14:1045-1052. CrossRef Medline

Homayoun H, Moghaddam B (2007) NMDA receptor hypofunction produces opposite effects on prefrontal cortex interneurons and pyramidal neurons. J Neurosci 27:11496-11500. CrossRef Medline

Johnson LA, Euston DR, Tatsuno M, McNaughton BL (2010) Stored-trace reactivation in rat prefrontal cortex is correlated with down-to-up state fluctuation density. J Neurosci 30:2650-2661. CrossRef Medline

Jones BF, Witter MP (2007) Cingulate cortex projections to the parahippocampal region and hippocampal formation in the rat. Hippocampus 17:957-976. CrossRef Medline

Jung MW, Qin Y, McNaughton BL, Barnes CA (1998) Firing characteristics of deep layer neurons in prefrontal cortex in rats performing spatial working memory tasks. Cereb Cortex 8:437-450. CrossRef Medline

Kloosterman F, Davidson TJ, Hale G, Layton SP, Gomperts SN, Nguyen DP, Wilson MA (2009) Micro-drive array for chronic in vivo recording: drive fabrication. J Vis Exp:e1094. CrossRef Medline

Knierim JJ (2002) Dynamic interactions between local surface cues, distal landmarks, and intrinsic circuitry in hippocampal place cells. J Neurosci 22:6254-6264. Medline

Knierim JJ, Rao G (2003) Distal landmarks and hippocampal place cells: effects of relative translation versus rotation. Hippocampus 13:604-617. CrossRef Medline

Knierim JJ, Kudrimoti HS, McNaughton BL (1998) Interactions between idiothetic cues and external landmarks in the control of place cells and head direction cells. J Neurophysiol 80:425-446. Medline

Kolb B, Walkey J (1987) Behavioural and anatomical studies of the posterior parietal cortex in the rat. Behav Brain Res 23:127-145. CrossRef Medline

Kolb B, Buhrmann K, McDonald R, Sutherland RJ (1994) Dissociation of the medial prefrontal, posterior parietal, and posterior temporal cortex for spatial navigation and recognition memory in the rat. Cereb Cortex 4:664-680. CrossRef Medline

McCormick DA, Connors BW, Lighthall JW, Prince DA (1985) Comparative electrophysiology of pyramidal and sparsely spiny stellate neurons of the neocortex. J Neurophysiol 54:782-806. Medline

McNaughton BL, Mizumori SJ, Barnes CA, Leonard BJ, Marquis M, Green EJ (1994) Cortical representation of motion during unrestrained spatial navigation in the rat. Cereb Cortex 4:27-39. CrossRef Medline

McNaughton BL, Knierim JJ, Wilson MA (1995) Vector encoding and the vestibular foundations of spatial cognition: neurophysiological and computational mechanisms. In: The cognitive neurosciences (Gazzaniga MS, ed), pp 585-595. Cambridge, MA: MIT.

McNaughton BL, Battaglia FP, Jensen O, Moser EI, Moser MB (2006) Path integration and the neural basis of the 'cognitive map'. Nat Rev Neurosci 7:663-678. CrossRef Medline

Meier RK, Dieringer N (1993) The role of compensatory eye and head movements in the rat for image stabilization and gaze orientation. Exp Brain Res 96:54-64. Medline

Nakamura K (1999) Auditory spatial discriminatory and mnemonic neurons in rat posterior parietal cortex. J Neurophysiol 82:2503-2517. Medline

Nguyen DP, Layton SP, Hale G, Gomperts SN, Davidson TJ, Kloosterman F, Wilson MA (2009) Micro-drive array for chronic in vivo recording: tetrode assembly. J Vis Exp:e1098. CrossRef Medline

Nitz DA (2006) Tracking route progression in the posterior parietal cortex. Neuron 49:747-756. CrossRef Medline

Nitz DA (2012) Spaces within spaces: rat parietal cortex neurons register 
position across three reference frames. Nat Neurosci 15:1365-1367. CrossRef Medline

O’Keefe J, Dostrovsky J (1971) The hippocampus as a spatial map. Preliminary evidence from unit activity in the freely-moving rat. Brain Res 34: 171-175. CrossRef Medline

O'Keefe J, Nadel L (1978) The hippocampus as a cognitive map. Oxford, UK: Clarendon.

Paxinos G, Watson C (1998) The rat brain in stereotaxic coordinates, Ed 4. New York: Academic.

Reep RL, Chandler HC, King V, Corwin JV (1994) Rat posterior parietal cortex: topography of corticocortical and thalamic connections. Exp Brain Res 100:67-84. CrossRef Medline

Robinson DL, Goldberg ME, Stanton GB (1978) Parietal association cortex in the primate: sensory mechanisms and behavioral modulations. J Neurophysiol 41:910-932. Medline

Rogers JL, Kesner RP (2006) Lesions of the dorsal hippocampus or parietal cortex differentially affect spatial information processing. Behav Neurosci 120:852-860. CrossRef Medline

Salinas E, Abbott LF (1995) Transfer of coded information from sensory to motor networks. J Neurosci 15:6461-6474. Medline

Sato N, Sakata H, Tanaka YL, Taira M (2006) Navigation-Associated Medial Parietal Neurons in Monkeys. Proc Natl Acad Sci U S A 103:1700117006. CrossRef Medline

Save E, Poucet B (2000) Involvement of the hippocampus and associative parietal cortex in the use of proximal and distal landmarks for navigation. Behav Brain Res 109:195-206. CrossRef Medline

Sharp PE, Blair HT, Cho J (2001a) The anatomical and computational basis of the rat head-direction cell signal. Trends Neurosci 24:289-294. CrossRef Medline

Sharp PE, Tinkelman A, Cho J (2001b) Angular velocity and head direction signals recorded from the dorsal tegmental nucleus of Gudden in the rat: implications for path integration in the head direction cell circuit. Behav Neurosci 115:571-588. CrossRef Medline

Skaggs WE, Knierim JJ, Kudrimoti HS, McNaughton BL (1995) A model of the neural basis of the rat's sense of direction. Adv Neural Inf Process Syst 7:173-180. Medline

Snyder LH, Grieve KL, Brotchie P, Andersen RA (1998) Separate body- and world-referenced representations of visual space in parietal cortex. Nature 394:887-891. CrossRef Medline

Taube JS (1995) Head direction cells recorded in the anterior thalamic nuclei of freely moving rats. J Neurosci 15:70-86. Medline evel3
Torrealba F, Vald és JL (2008) The parietal association cortex of the rat. Biol Res 41:369-377. CrossRef Medline0

Vass LK, Epstein RA (2013) Abstract representations of location and facing direction in the human brain. J Neurosci 33:6133-6142. CrossRef Medline

Vogt BA, Miller MW (1983) Cortical connections between rat cingulate cortex and visual, motor, and postsubicular cortices. J Comp Neurol 216 : 192-210. CrossRef Medline

Wallace DJ, Greenberg DS, Sawinski J, Rulla S, Notaro G, Kerr JN (2013) Rats maintain an overhead binocular field at the expense of constant fusion. Nature 498:65-69. CrossRef Medline

Wang Q, Burkhalter A (2007) Area map of mouse visual cortex. J Comp Neurol 502:339-357. CrossRef Medline

Wang Q, Sporns O, Burkhalter A (2012) Network analysis of corticocortical connections reveals ventral and dorsal processing streams in mouse visual cortex. J Neurosci 32:4386-4399. CrossRef Medline

Whitlock JR, Pfuhl G, Dagslott N, Moser MB, Moser Edvard I (2012) Functional split between parietal and entorhinal cortices in the rat. Neuron 73:789-802. CrossRef Medline

Whitlock JR, Sutherland RJ, Witter MP, Moser MB, Moser EI (2008) Navigating from hippocampus to parietal cortex. Proc Natl Acad Sci U S A 105:14755-14762. CrossRef Medline

Wills TJ, Cacucci F, Burgess N, O’Keefe J (2010) Development of the hippocampal cognitive map in preweanling rats. Science 328:1573-1576. CrossRef Medline

Wilson MA, McNaughton BL (1993) Dynamics of the hippocampal ensemble code for space. Science 261:1055-1058. CrossRef Medline

Woloszyn L, Sheinberg DL (2012) Effects of long-term visual experience on responses of distinct classes of single units in inferior temporal cortex. Neuron 74:193-205. CrossRef Medline

Xing J, Andersen RA (2000) Models of the posterior parietal cortex which perform multimodal integration and represent space in several coordinate frames. J Cogn Neurosci 12:601-614. CrossRef Medline

Zar J (1999) Biostatistical analysis, Ed 4. Upper Saddle River, NJ: Prentice Hill.

Zilles K (1985) The cortex of the rat. New York: Springer.

Zipser D, Andersen RA (1988) A back-propagation programmed network that simulates response properties of a subset of posterior parietal neurons. Nature 331:679-684. CrossRef Medline 